\title{
SOURCE STUDY OF THE 1906 SAN FRANCISCO EARTHQUAKE
}

\author{
By David J. Wald*, Hiroo Kanamori, Donald V. Helmberger and \\ Thomas H. Heaton
}

\begin{abstract}
All quality teleseismic recordings of the great 1906 San Francisco earthquake archived in the 1908 Carnegie Report by the State Earthquake Investigation Commission were scanned and digitized. First order results were obtained by comparing complexity and amplitudes of teleseismic waveforms from the 1906 earthquake with well calibrated, similarly located, more recent earthquakes (1979 Coyote Lake, 1984 Morgan Hill, and 1989 Loma Prieta earthquakes) at nearly co-located modern stations. Peak amplitude ratios for calibration events indicated that a localized moment release of about 1 to $1.5 \times$ $10^{27}$ dyne-cm was responsible for producing the peak the teleseismic body wave arrivals. At longer periods (50 to $80 \mathrm{sec}$ ), we found spectral amplitude ratios of the surface waves require a total moment release between 4 and $6 \times 10^{27}$ dyne-cm for the 1906 earthquake, comparable to previous geodetic and surface wave estimates (Thatcher, 1975). We then made a more detailed source analysis using Morgan Hill $S$ body waves as empirical Green's Functions in a finite fault subevent summation. The Morgan Hill earthquake was deemed most appropriate for this purpose as its mechanism is that of the 1906 earthquake in the central portion of the rupture. From forward and inverse empirical summations of Morgan Hill Green's functions, we obtained a good fit to the best quality teleseismic waveforms with a relatively simple source model having two regions of localized strong radiation separated spatially by about $110 \mathrm{~km}$. Assuming the 1906 epicenter determined by Bolt (1968), this corresponds with a large asperity (on the order of the Loma Prieta earthquake) in the Golden Gate/San Francisco region and one about three times larger located northwest along strike between Point Reyes and Fort Ross. This model implies that much of the 1906 rupture zone may have occurred with relatively little 10 to $20 \mathrm{sec}$ radiation. Consideration of the amplitude and frequency content of the 1906 teleseismic data allowed us to estimate the scale length of the largest asperity to be less than about $40 \mathrm{~km}$. With rough constraints on the largest asperity (size and magnitude) we produced a suite of estimated synthetic ground velocities assuming a slip distribution similar to that of the Loma Prieta earthquake but with three times as much slip. For purposes of comparison with the recent, abundant Loma Prieta strong motion data set, we "moved" the largest 1906 asperity into Loma Prieta region. Peak ground velocity amplitudes are substantially greater than those recorded during the Loma Prieta earthquake, and are comparable to those predicted by the attenuation relationship of Joyner and Boore (1988) for a magnitude $M_{W}=7.7$ earthquake.
\end{abstract}

\section{INTRODUCTION}

The great 1906 San Francisco earthquake began an era in earthquake seismology. Following this earthquake, direct observations of surface displacement combined with the analysis of the surrounding crustal deformation led Reid (1910) to formulate the elastic rebound theory. Although much has been learned from the numerous studies of the 1906 earthquake, a systematic analysis of the recorded teleseismic body and surface waveforms has not been made. Yet, the

*Now at U.S. Geological Survey, 525 S. Wilson Avenue, Pasadena, CA 91106. 
seismic recordings of the 1906 earthquake have been well preserved in the Atlas of the 1908 Carnegie Report by the State Earthquake Investigation Commission (Lawson, 1908), hereafter referred to as the Atlas or the Report. It is the authoritative reference and summary of the 1906 earthquake, including geological observations, the effects of ground shaking, and all the data collected following the earthquake. In this study, we revisit the waveform data set contained in the Atlas and analyze the data in the context of modern source analysis.

The need to understand the ground motion hazard potential from earthquakes in the San Francisco area has been rekindled by the occurrence of and damage from the 1989 Loma Prieta earthquake. The Loma Prieta event has provided a valuable strong motion data set for analysis of source complexity and ground motion damage from a magnitude 7 earthquake. Unfortunately, local strong ground motion data from the (much larger) 1906 earthquake was limited to one off-scale, partial recording on the Ewing three-component seismograph at Mt. Hamilton (Boore, 1977). Few strong motion recordings have been made from any large strike-slip earthquakes. However, it is possible to obtain source information relevant to understanding the local strong motions through analysis of the teleseismic data.

In a separate study of the Loma Prieta earthquake, Wald et al. (1991) inverted the broadband teleseismic and local strong motion to determine the temporal and spatial distribution of slip. Separate inversions of the teleseismic data (periods 3 to $30 \mathrm{sec}$ ) and strong motion data (periods 1 to $5 \mathrm{sec}$ ) resulted in similar rupture models. Hence, the broadband teleseismic data has the capability of providing important constraints on the nature of the strong motions at long periods, independent of the strong motion recordings. In the study that follows, we apply this insight to the 1906 earthquake, although clearly the quality and bandwidth of the historic data are not as impressive as the modern digital, broadband data.

Our study focuses on several important unresolved issues relevant to the 1906 rupture. Was the 1906 rupture complex or were there large portions of the fault where rupture was fairly uniform? What was the nature and location of fault asperities? As we will show, the body waveforms are fairly simple considering the rupture duration expected for such a large rupture length (at least 300 , and likely $430 \mathrm{~km}$ ). Did the Loma Prieta section of the fault have a dip-slip component? The geodetic study of Segall and Lisowski (1990) requires a few meters of strike-slip motion for 1906 along the Loma Prieta segment of the fault, but their data does not rule out a thrust component comparable to the Loma Prieta earthquake at greater depths. Is there evidence for a dip-slip component in this or other portions of the fault? We address these issues in this study.

Processing and interpreting the turn-of-the-century seismic data recorded presented many challenges. However, we believe that the historic data are valuable despite their limitations, and thus, it is desirable to try and obtain as much information from them as possible considering the importance of the 1906 San Francisco earthquake. Hence, we have revisited the data available for the 1906 earthquake in an effort to place constraints on the nature of that rupture, relate the radiated seismic energy to fault breakage and geodetic offset measurements, and to determine its relationship to the Loma Prieta rupture.

Although the records of the 1906 earthquake alone may be insufficient to 
resolve the above questions, the use of records from the Loma Prieta, Morgan Hill, and Coyote Lake earthquakes first as calibration events, and then as empirical Green's functions assists in extracting important information from this unique data set. The analysis of the teleseismic data proves useful in answering questions about fault rupture style on the San Andreas Fault and asperity positions in addition to allowing an estimation of strong ground motions likely experienced during the 1906 earthquake.

\section{OVERVteW OF PRevious STUdies}

The significance of the 1906 earthquake resulted in careful collection and mapping of the geologic, geodetic, seismic, and sociological data. A wealth of investigations have been made, and scientific studies of this event still appear in the geophysical literature occasionally. The occurrence of the 1989 Loma Prieta earthquake rejuvenated interest in previous San Francisco Bay area earthquakes, particularly the 1906 event. Most recently, reanalysis has been made of both the geodetic (Segall and Lisowski, 1990) and surface offset data (Prentice and Schwartz, 1991). Constraints on the rupture characteristics are provided by previous studies of the epicenter, surface offset, geodetic slip, and mapped isoseismal distributions.

\section{Surface Offset and Geodetic Observations}

The 1906 surface rupture is known to have ruptured about $300 \mathrm{~km}$ from San Juan Bautista (or Chittenden) to Point Arena (Fig. 1). It is commonly assumed that the rupture continued offshore for $140 \mathrm{~km}$ to Cape Mendocino. This was initially based on an observation of surface rupture at Shelter Cover (near Point Delgada, Fig. 1), although the amount of slip at Point Delgada was never documented, and it might not be of tectonic origin. Other equivocal evidence for offshore rupture is suggested by other observations, but questions about the offshore extension of rupture have not been eliminated. Observations that support the extension of rupture offshore include the impressive ground shaking and damage in the Cape Mendocino region as shown by the 8 to 9 Modified Mercalli isoseismal values (Fig. 2). In addition, a linear zone of strong shaking (X on the Rossi-Forel scale), narrower but similar to regions along the fault trace further south, is evident in the Atlas map of apparent intensities but is not so clear because of the limited number of data points in Figure 2. The Report also documents many strongly felt aftershocks within the same region, many of which occurred locally considering they were not reported at locations toward the southeast. Furthermore, geodetic modeling by Thatcher and Lisowski (1987a) favors about 4 to $6 \mathrm{~m}$ of displacement to a depth of $10 \mathrm{~km}$ on the offshore region to satisfy the distortion of the geodetic network onshore to the east.

Alternatively, the strong shaking along the extension of the northwest terminus of a rupture propagating over $200 \mathrm{~km}$ in that direction would be expected from the effects of source directivity. Likewise, aftershocks commonly occur well off the end of the rupture zone (i.e., the 1992 Landers earthquake) and thus do not necessarily reflect the true source dimension. Concerning the geodetic evidence for large 1906 offsets offshore, the data of Thatcher and Lisowski (1987a) spanned a very long duration from about 1880 to 1940 and were, of course, limited to a one-sided, onshore network well east of the rupture. Therefore, their resolution is not good, and any displacement observed was not 


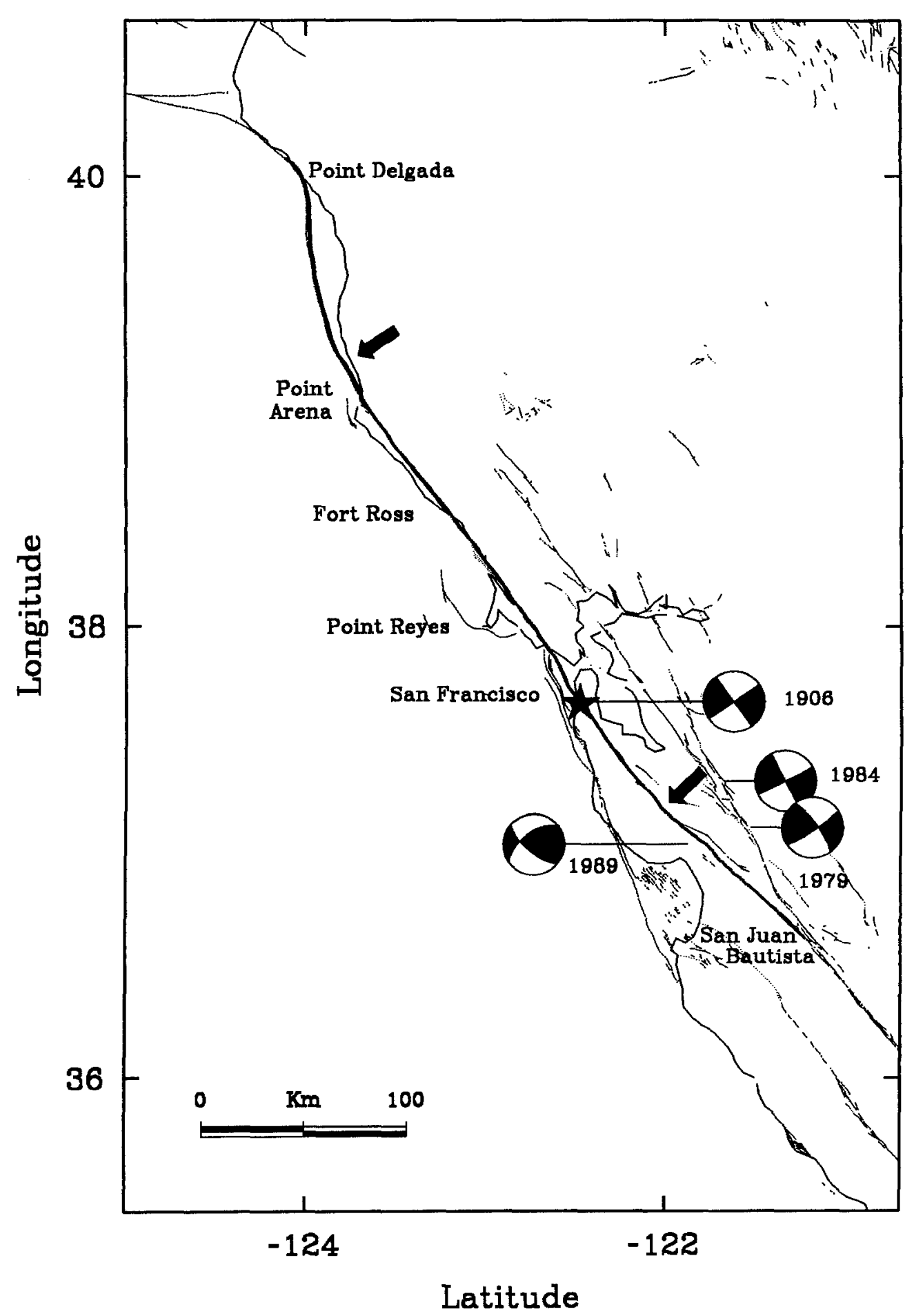

FIG. 1. Location map showing rupture length (thick line) of the 1906 San Francisco earthquake. Arrows refer to significant changes in the strike of the San Andreas Fault. The epicenter of Bolt (1968) is represented as a star. Focal mechanisms indicate location and faulting geometry of calibration events. 


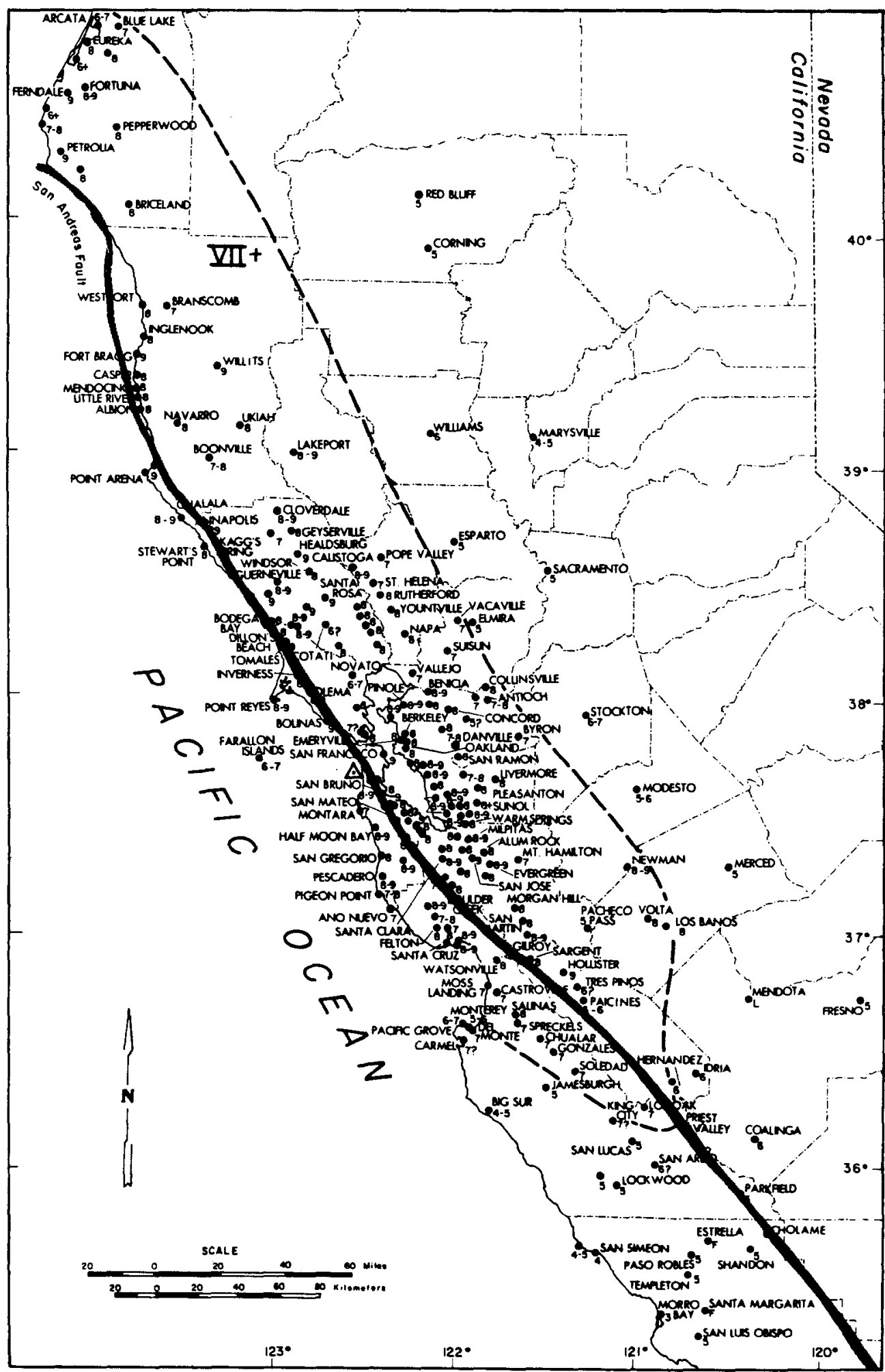

FIG. 2. Modified Mercalli shaking intensity map (Toppozada and Parke, 1982). The thick line represents the trace of the San Andreas Fault and the extent of intensity VII + is indicated with a dashed line. 
necessarily coseismic. There is no clear documented evidence for tectonic surface rupture associated with the 1906 earthquake at the northernmost end of the assumed rupture, nor have any paleo-earthquakes been associated with the San Andreas north of Point Arena (D. Merrits, personal communication, 1991). Furthermore, McLaughlin et al. (1979) discuss adularia veins (dated older than 10 million years BP) that cross the terraine boundary at Point Delgada. According to McLaughlin et al. (1979) these northeast striking veins are crossed with a steeply dipping northwest-striking fault that many workers regard as the on-land extension of the San Andreas Fault. However, the mineralization and cross-cutting relation of the faults, which show little or no offset, indicate that no significant motion has occurred along the purported San Andreas Fault trace since late middle Miocene time. Finally, the commonly assumed connection of the San Andreas Fault from Point Arena to Point Delgada, requires a bend in the San Andreas strike more significant $\left(>20^{\circ}\right)$ than anywhere else along the northern portion of the fault. It might be expected to behave as a source of high-frequency radiation during a rupture that traversed such a geometric obstacle. There is little significant evidence for radiation from this section of the fault in the teleseismic recordings. The shorter $(300 \mathrm{~km})$ rupture length is more consistent with the effective rupture length of $240 \mathrm{~km}$ determined by BenMenahem (1978) for this earthquake based on surface wave analysis. This is not to suggest that the rupture did not continue offshore, but rather to point out that any conclusion on this issue is not without question.

In order to model this event, we divided the rupture length into three segments: the northwest, central, and southeast portions of the full rupture. The arrows on Figure 1 depict the boundaries between these segments. Note that there is a significant change in strike between the segments going from $\mathrm{N} 15^{\circ} \mathrm{W}$ in the northeast to $\mathrm{N} 35^{\circ} \mathrm{W}$ in the central section to $\mathrm{N} 50^{\circ} \mathrm{W}$ in the southeast. In the central portion of the rupture, surface offset averaged nearly 4 $m$ from south of San Francisco to Point Arena where it heads offshore. In the southeastern section, the surface offset is difficult to quantify and is much smaller than to the northwest. The historical data provides no unequivocal estimates of surface slip, although offset in Wright's tunnel amounts to 1 to $1 \frac{1}{2} \mathrm{~m}$ and is considered one of the more reliable measurements (Prentice and Schwartz, 1991). The geodetic data require the slip at depth to be about 2 to $3 \mathrm{~m}$ from San Juan Bautista through the Loma Prieta section and between about 5 and $7 \mathrm{~m}$ along the central segment (Thatcher, 1975).

\section{Seismic Data}

Epicenter. For modeling purposes, we chose the epicenter given by Bolt (1968) that was based on local timing observations, stopping of astronomical clocks, a local strong motion recording at Mt. Hamilton, and teleseismic $P$ and $S-P$ travel times. The location is near that of the 1957 Daly City earthquake $(M=5.7)$ epicenter and is shown as an asterisk in Figure 1. Our subsequent modeling of the body waves supports this location.

Strong Motions. The only strong motion data written during the 1906 earthquake was on a Ewing three-component seismograph at Lick Observatory on Mt. Hamilton, an epicentral distance of about $85 \mathrm{~km}$. Although the traces went off scale after only $10 \mathrm{sec}$, Boore (1977) was able to model features of the recording and determine that the polarities and timing were consistent with the epicenter determined by Bolt (1968). Boore (1977) also concluded that the most 
massive faulting responsible for the strong motions at Mt. Hamilton came from at least $75 \mathrm{~km}$ away and were dominated by surface waves. In addition to the Mt. Hamilton strong motion recording, several Ewing duplex pendulum recordings were preserved. The records at Mt. Hamilton and Berkeley were useful to Boore (1977) in corroborating waveform polarities at the Mt. Hamilton station.

Local Magnitude. The duplex pendulum records mentioned above, in addition to several others (Alameda, San Jose, Oakland, and Carson City, Nev.) and a simple pendulum at Yountville were used by Jennings and Kanamori (1979) to estimate the local magnitude by extrapolating the seismoscope-style recordings to the maximum response of the standard Wood-Anderson instrument. The Wood-Anderson response is most appropriate for quantifying the nature of strong ground motions, because its period and damping are such that it is sensitive to motions in the frequency range of most interest to earthquake engineering. Considering the uncertainties involved, Jennings and Kanamori assigned a $M_{L}$ range of $6 \frac{3}{4}$ to $7 \frac{1}{4}$, although analysis of the Carson City recording, deemed to be most reliable, gave a $M_{L}=7.2$. It is fortunate to have an $M_{L}$ estimate for 1906 to compare with other large strike-slip earthquakes since the local magnitude determination is made at distances relatively near the source, and hence, the time history input to the instrument is more representative of the duration and frequency content of near-source ground motions than other magnitude scales.

Surface Wave Magnitude. An important issue that arose during this study involved the value of the surface wave magnitude $\left(M_{S}\right)$ for the 1906 earthquake. The $M_{S}$ value of $8 \frac{1}{4}$ (or 8.3) often quoted for 1906 is an overestimate, as stated by Abe and Noguchi (1983), and can be explained by two factors. First, there is an azimuthal bias toward larger $M_{S}$ values from California to stations in Europe and second, the bias is exacerbated by the use of undamped instruments during that time period. The azimuthal bias can be demonstrated with $M_{S}$ determinations for the 1979 Imperial Valley and 1989 Loma Prieta earthquakes (Fig. 3). The $M_{S}$ values are plotted as a function of station azimuth as given in the monthly Preliminary Determination of Epicenters (PDEs) for the Loma Prieta and Imperial Valley events, and directly from Richter's notebook for the 1906 values.

Note that within the narrow range of azimuths from which the $1906 M_{S}$ determination was made $\left(20^{\circ}\right.$ to $\left.90^{\circ}\right)$, the other events have very large $M_{S}$ values and would provide a biased estimate of the average $M_{S}$ value. Using only magnitude values within this azimuthal range yields an $M_{S}=7.4$ for the 1989 Loma Prieta earthquake, whereas the computed value should be 7.0. As a side note, for the individual station $M_{S}$ values published in the PDEs and shown in Figure 3, the average Loma Prieta $M_{S}$ is 7.0 , not 7.1 as commonly accepted. Similarly, the 1979 Imperial Valley $M_{S}$ value of 6.9 was determined largely from European stations, yielding a biased value. For azimuths limited from $20^{\circ}$ to $90^{\circ}, M_{S}$ would be 7.1. Also note that for these two events, the moment magnitudes $M_{W}$ computed from the seismic moments determined from waveform modeling are significantly smaller than $M_{S}$. For the Loma Prieta earthquake, $M_{W}=6.9$ (Wald et al., 1991) and $M_{W}=6.4$ for the Imperial Valley event (Hartzell and Heaton, 1983). Because for most events in this magnitude range $M_{S}$ is approximately the same as $M_{W}$, the above disparity between $M_{S}$ and $M_{W}$ for these two events suggests that the $M_{S}$ values for these two events are overestimated. 

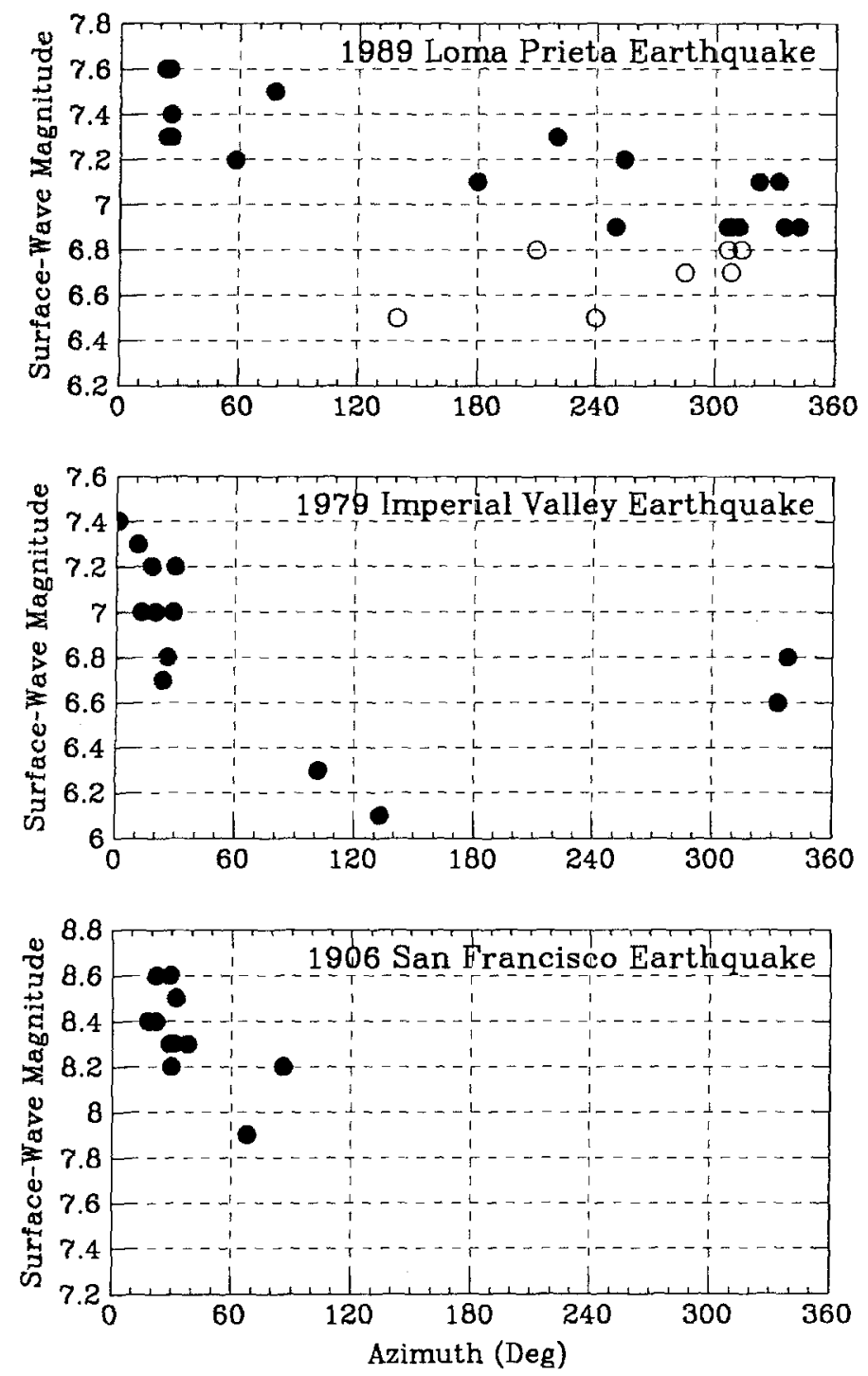

FIG. 3. Surface wave magnitudes $\left(M_{S}\right)$ as a function of station azimuth for the (a) 1989 Loma Prieta earthquake, (b) 1979 Imperial Valley earthquake, and (c) the 1906 San Francisco earthquake. For (a), open circles are values that were not used in the computation of the official PDE $M_{S}=7.1$ calculation.

We found this azimuthal trend holds true for all other moderate to large California earthquakes (with the exception of the $1980 M_{S}=8.0$ Eureka event) and is thus likely to be independent of focal mechanism. Loma Prieta has a good distribution of stations and only a slight azimuthal bias, and therefore, only a 0.1 unit difference between $M_{S}$ and $M_{W}$. Imperial Valley has a considerable azimuthal bias and consequently shows a 0.5 unit difference between $M_{S}$ and $M_{W}$.

Finally, the $1906 M_{S}$ determination has both a severe azimuthal bias and in addition is further biased by the use of undamped instruments as suggested by the work of Abe and Noguchi (1983). They recognized that $M_{S}$ determinations 
during the period from 1904 to 1906 were 0.5 magnitude units too large. They attributed this bias to the combined use of damped and undamped seismographs (undamped were slowly phased out). Abe and Noguchi (1983) used (undamped) Milne instrument recordings with a correction for damping and obtained $M_{S}=7.8$ for the San Francisco earthquake. At the time, Milne instruments had a better worldwide (hence azimuthal) coverage than damped instruments for 1906. Most $M_{S}$ magnitudes based on damped instruments relied heavily on European stations that clearly show a path bias for events from California (Gutenberg, 1955).

An $M_{S}$ value of $7 \frac{3}{4}$ is consistent with the $M_{W}=7.7$ estimate of Thatcher (1975) based on amplitudes of 50 to 100 -sec period surface waves at (stations ZIE, UPP, and GOT). It is also in agreement with the geodetic data that gave an $M_{W}=7.7$ (Thatcher and Lisowski, 1987a) from their estimated moment of $5 \times 10^{27}$ dyne-cm. Ben-Menahem (1978) found the seismic potency to be 25,000 $\mathrm{m} / \mathrm{km}^{2}$, based on from modeling 50 to $100 \mathrm{sec}$ surface waves. Using the same average rigidity, $\mu=3.0 \times 10^{11} \mathrm{dyne} / \mathrm{cm}^{2}$, as Thatcher (1975) this implies a seismic moment of $7.5 \times 10^{27}$ dyne-cm $\left(M_{W}=7.9\right)$.

The implication of the lower $M_{S}=7 \frac{3}{4}$ is very important, in that the moment magnitude equivalent of $M_{S}=7 \frac{3}{4}$ requires an average slip based on the estimated rupture area on the order of several meters, compatible with surface and geodetic observations. A moment magnitude of $8 \frac{1}{4}$ requires an average of about $15 \mathrm{~m}$ over the entire rupture length, even assuming rupture along the maximum estimated length $(450 \mathrm{~km})$ and a conservatively large average width of 15 $\mathrm{km}$. This is much larger than the geodetic and surface offset observations allow.

DATA

\section{Historical Data}

The 1906 earthquake was recorded at 96 stations around the world. The data from these stations were preserved in the Report and nearly all at the original recording size. Absolute time was preserved at most stations and time corrections were provided along with instrument damping, magnification, and free period constants. An example of the quality of the original analogue data contained in the Atlas is shown in Figure 4 for the station Göttingen, Germany as recorded on a Wiechert inverted pendulum instrument.

The waveforms were scanned and digitized, and care was taken to remove the instrument pen arc and to preserve absolute timing. In addition to the $1906 \mathrm{San}$ Francisco data, analogue recordings of more recent events were digitized from long-period World-Wide Standardized Seismic Network (WWSSN) stations to be used for calibration and empirical Green's functions. Those data will be discussed in a later section.

\section{Instrument Responses}

Useful data were obtained for 12 stations, the locations of which are given in Table 1 and shown in Figure 5. The most useful records were written by Wiechert and Bosch-Omori instruments. The Wiechert instrument response can be accurately reproduced; the free period is about 5 to $15 \mathrm{sec}$ and the magnification is on the order of 150 times. The Bosch-Omori instruments have free periods ranging from 20 to $30 \mathrm{sec}$ and magnifications near 20 times. The pendulum period, $T_{0}$, and damping constant, $h$, for each component are given in 


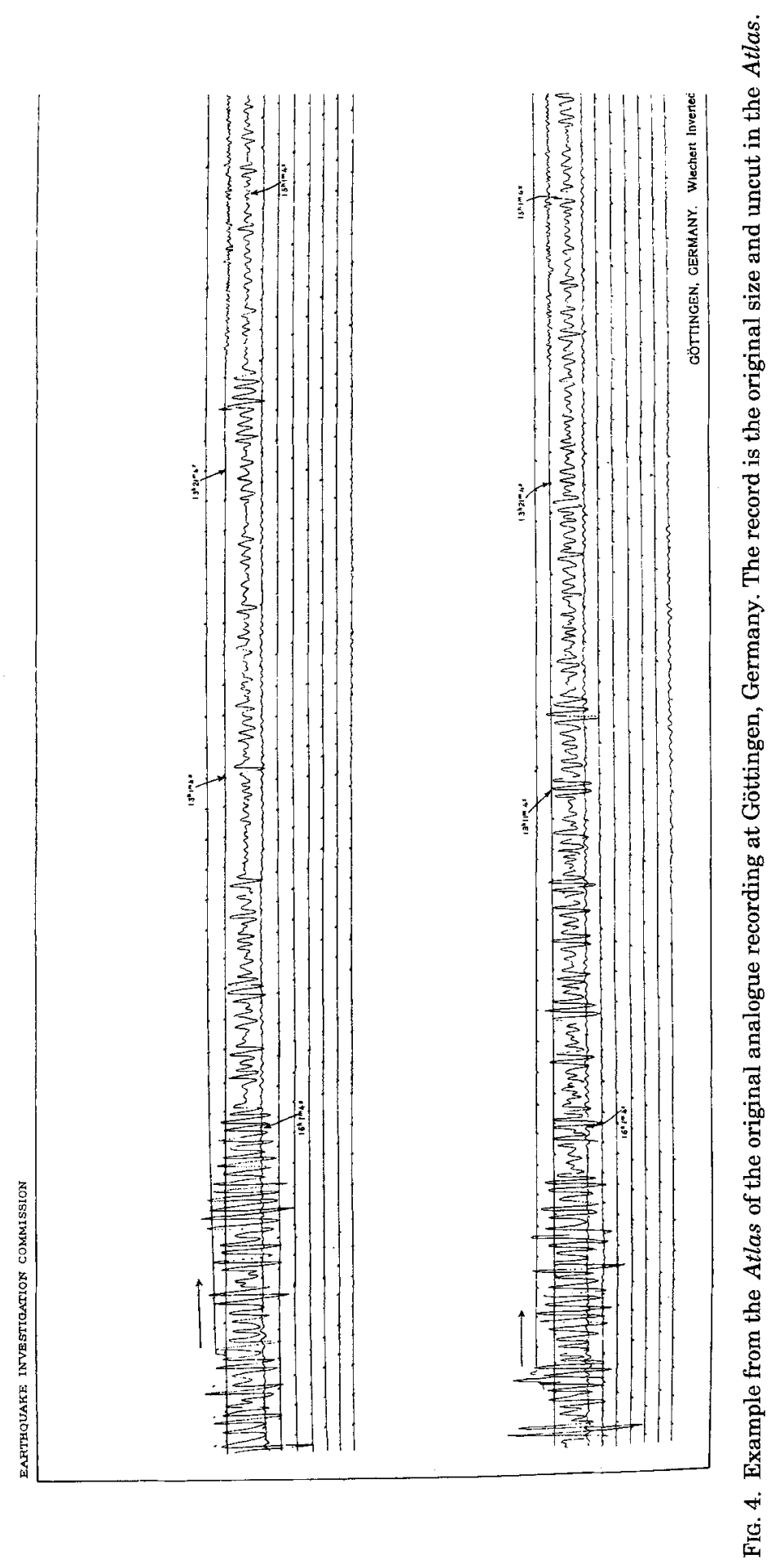




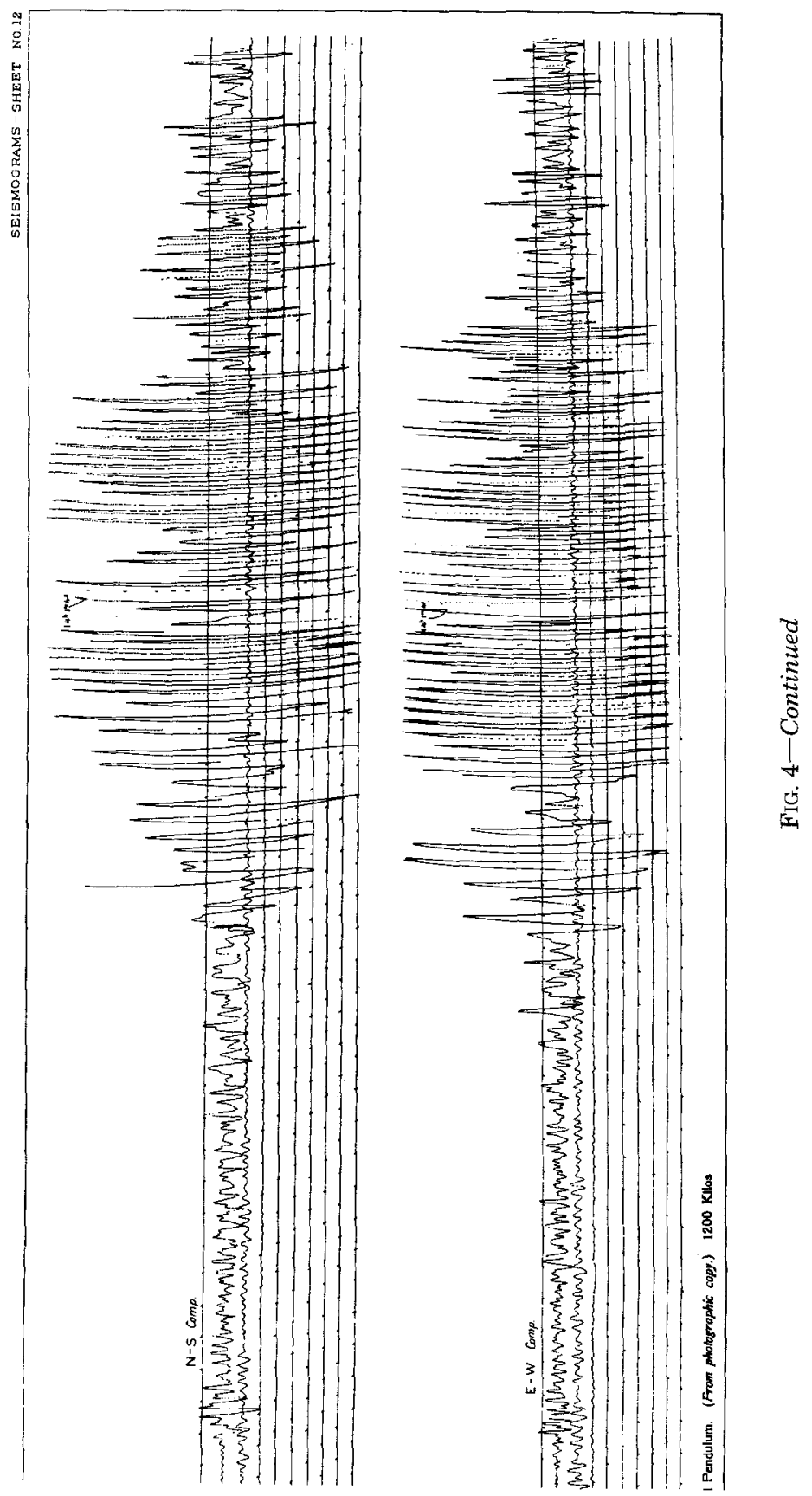



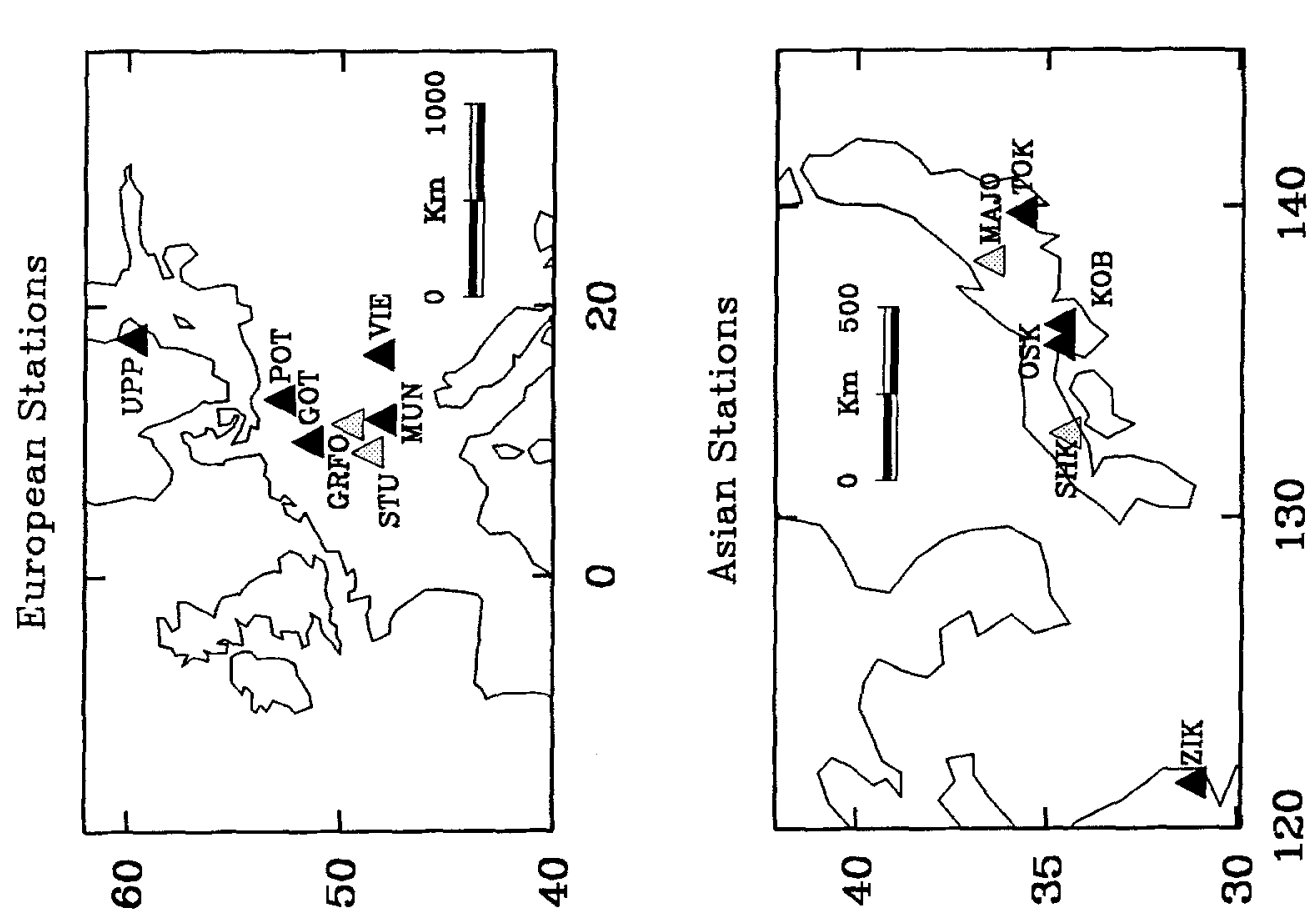

-
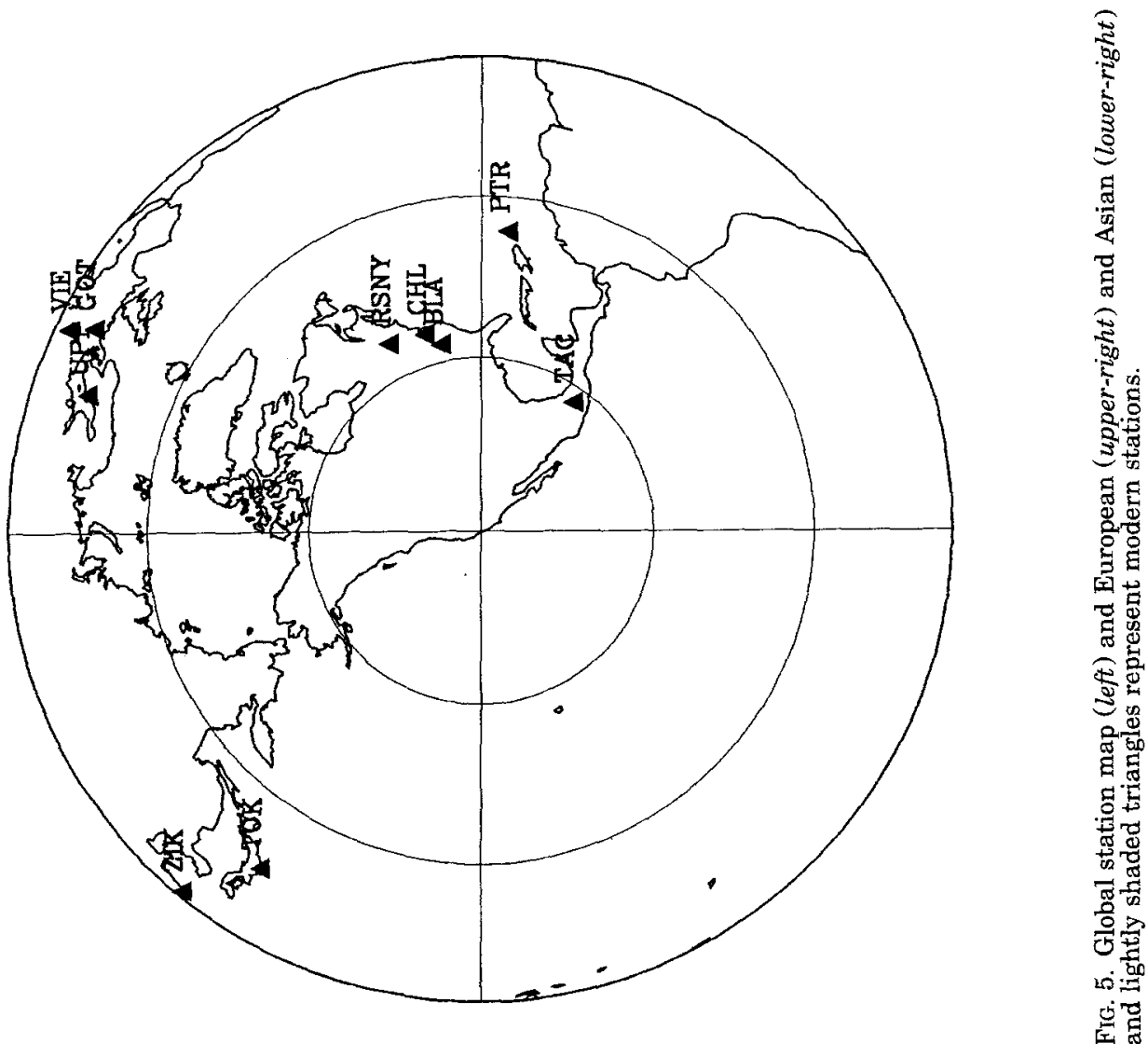
Table 2. The damping constant, $h$, is related to the damping ratio, $\epsilon$, given in the Report by the expression (e.g. Richter, 1958, p. 219)

$$
\epsilon=\exp \frac{\pi h}{\sqrt{1-h^{2}}}
$$

All values were contained in the Report, with the exception of the several damping constants given in Table 2 as .20. These values are estimated to be near .20 and reasonable deviations from this value modify the waveforms only slightly; the conclusions obtained in this study do not rely on the few stations with unknown damping constants. For the purpose of this study, we removed the mechanical instrument response and convolved in the WWSSN long-period response (with a gain of 1500) to facilitate comparisons with the recent calibration events. Therefore the waveforms shown, unless otherwise stated, are as if recorded on a WWSSN long-period instrument and amplitudes are given in

TABLE 1

Station Abbreviations and Parameters for 1906. Distances are with Respect to the Epicenter Determined by Bolt (1968) at 37.667 North Latitude and 122.480 West LongtTUde.

\begin{tabular}{lllrrrr}
\hline Station & \multicolumn{1}{c}{ Location } & Latitude & Longitude & $\begin{array}{c}\text { Distance } \\
\text { (Deg.) }\end{array}$ & Azimuth & $\begin{array}{c}\text { Back } \\
\text { Azimuth }\end{array}$ \\
\hline ALB & Albany, New York & 42.65 & -73.75 & 37.2 & 66.6 & 270.1 \\
CHL & Cheltenham, MD & 38.733 & -76.842 & 35.6 & 73.9 & 282.9 \\
GOT & Gottingen, Germany & 51.55 & 9.967 & 81.9 & 27.7 & 323.7 \\
KOB & Kobe, Japan & 34.683 & 136.167 & 77.5 & 304.2 & 52.8 \\
MUN & Munich, Germany & 48.150 & 11.608 & 85.3 & 28.9 & 324.1 \\
OSK & Osaka, Japan & 34.70 & 135.517 & 78.0 & 304.5 & 52.5 \\
POT & Potsdam, Germany & 52.883 & 13.067 & 81.9 & 25.4 & 325.9 \\
PTR & Puerto Rico, W.I. & 18.133 & -65.433 & 53.2 & 95.0 & 303.8 \\
TAC & Tacubaya, Mexico & 19.40 & -99.20 & 27.3 & 125.5 & 316.8 \\
TOK & Tokyo, Japan & 35.708 & 139.767 & 74.6 & 303.2 & 54.7 \\
UPP & Uppsala, Sweden & 59.858 & 17.626 & 77.4 & 19.4 & 328.6 \\
ZIK & Zi-ka-wei, China & 31.20 & 121.433 & 89.7 & 309.7 & 45.5 \\
\hline
\end{tabular}

TABLE 2

INSTRUMENT CONSTANTS FOR 1906 RECORDINGS

\begin{tabular}{llccc} 
Station & $\begin{array}{c}\text { Instrument } \\
\text { Type }\end{array}$ & $\begin{array}{c}\text { Period (To) } \\
\text { NS-EW }\end{array}$ & $\begin{array}{c}\text { Damping (h) } \\
\text { NS-EW }\end{array}$ & $\begin{array}{c}\text { Magnification } \\
\text { NS-EW }\end{array}$ \\
\hline ALB & Bosch-Omori & 30,30 & $.20, .20$ & 10,10 \\
CHL & Bosch-Omori & 20,25 & $.20, .20$ & $\mathbf{1 0 , 1 0}$ \\
GOT & Wiechert & 14,13 & $.39, .36$ & 172,152 \\
KOB & Omori & $35,-$ & $.20,-$ & $10,-$ \\
MUN & Wiechert & 12,12 & $.50, .50$ & 200,200 \\
OSK & Omori &,- 27 &,- .20 &,- 20 \\
POT & Wiechert & 14,14 & $.46, .46$ & 130,130 \\
PTR & Bosch-Omori & 21,21 & $.15, .15$ & 10,10 \\
TAC & Bosch-Omori & 17,17 & $.20, .20$ & $\mathbf{1 5}, 15$ \\
TOK & Omori &,- 42 &,- .20 &,- 30 \\
UPP & Wiechert & $6.8,5.3$ & $.33, .33$ & 270,230 \\
ZIK & Omori &,- 33 &,- .25 & -15 \\
\hline
\end{tabular}


millimeters. A comparison of the mechanical instrument responses used here with that of the WWSSN long-period instrument is shown in Helmberger et al., 1992.

Remarkably, the same instrument that recorded the 1906 earthquake at Gottingen, Germany recorded the 1989 Loma Prieta earthquake $\left(M_{W}=6.9\right)$. Although the instrument constants were given for 1906 in the Report and were available for 1989, they were nearly the same as in 1906 , with a slight change in the $T_{0}$, the natural period of the pendulum. Comparison of the two earthquake recordings is shown in Figure 6. The travel times are shown for body wave phases using Jeffreys-Bullen (1958) travel times and assuming the epicentral parameters for the 1906 earthquake of Bolt (1968). Note the changes in the vertical scale and the difference in the noise levels between the two events; only the larger arrivals are successfully retrieved by digitizing the analogue records for the Loma Prieta event. The $S$ waves are distinctly different. The Loma Prieta $S$ waveform is short in duration and is indicative of an oblique mechanism whereas the San Francisco $S$ wave has a much longer duration and an amplitude on average nearly 5 times larger. Observing the Loma Prieta $S$ wave on this instrument well above the noise level indicates that we should expect to see many subevents for 1906 on such an instrument if the San Francisco earthquake was comprised of many Loma Prieta style subevents.

Figure 7 shows the north and east components for station GOT after instrument normalization and convolution with the WWSSN long-period response. Again, expected body wave phase arrival times are given. The start time labels

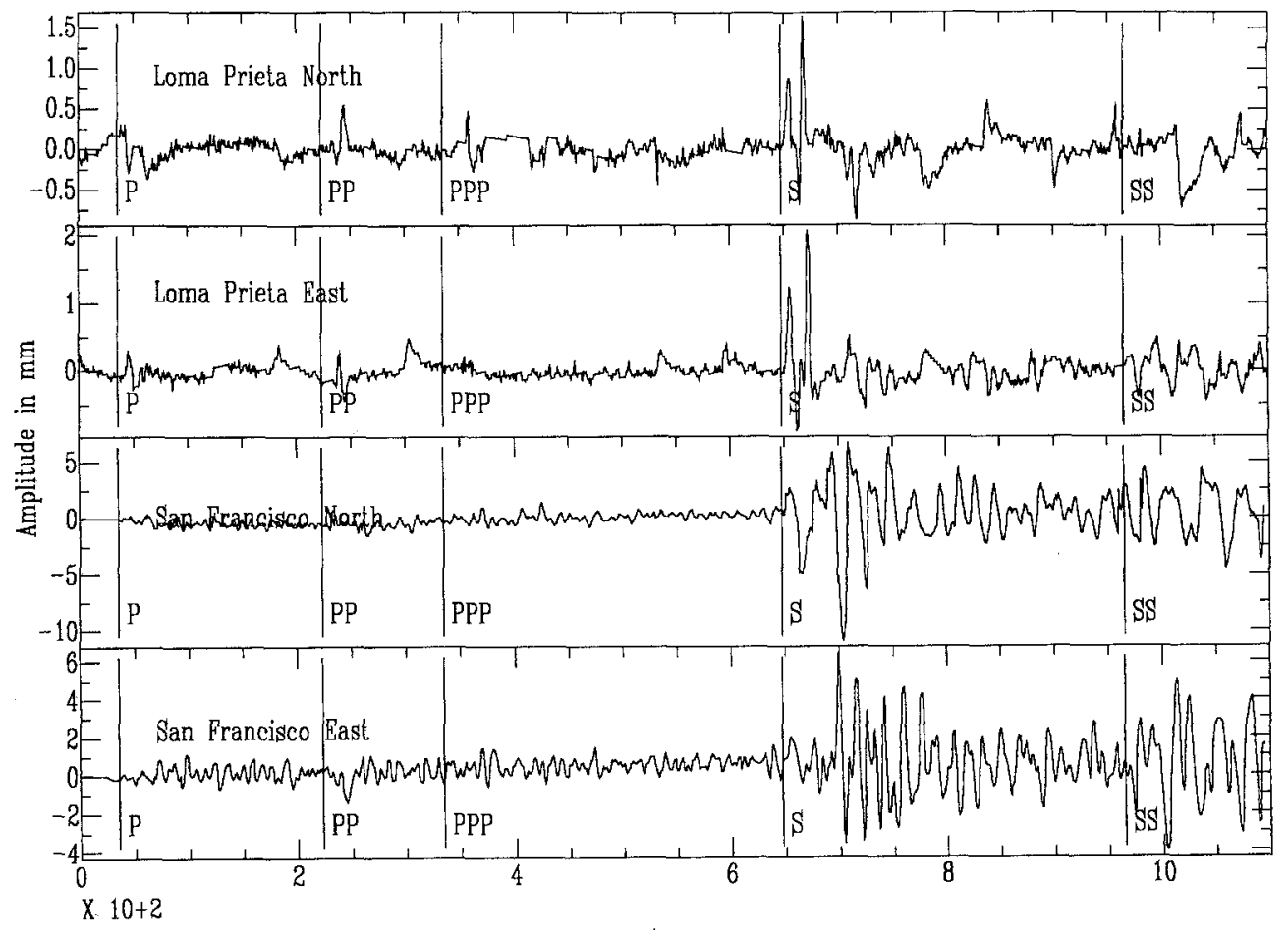

TIME - Seconds x 100

FIG. 6. Comparison of the 1989 Loma Prieta and 1906 San Francisco digitized recordings from the Wiechert seismograph at GOT. 


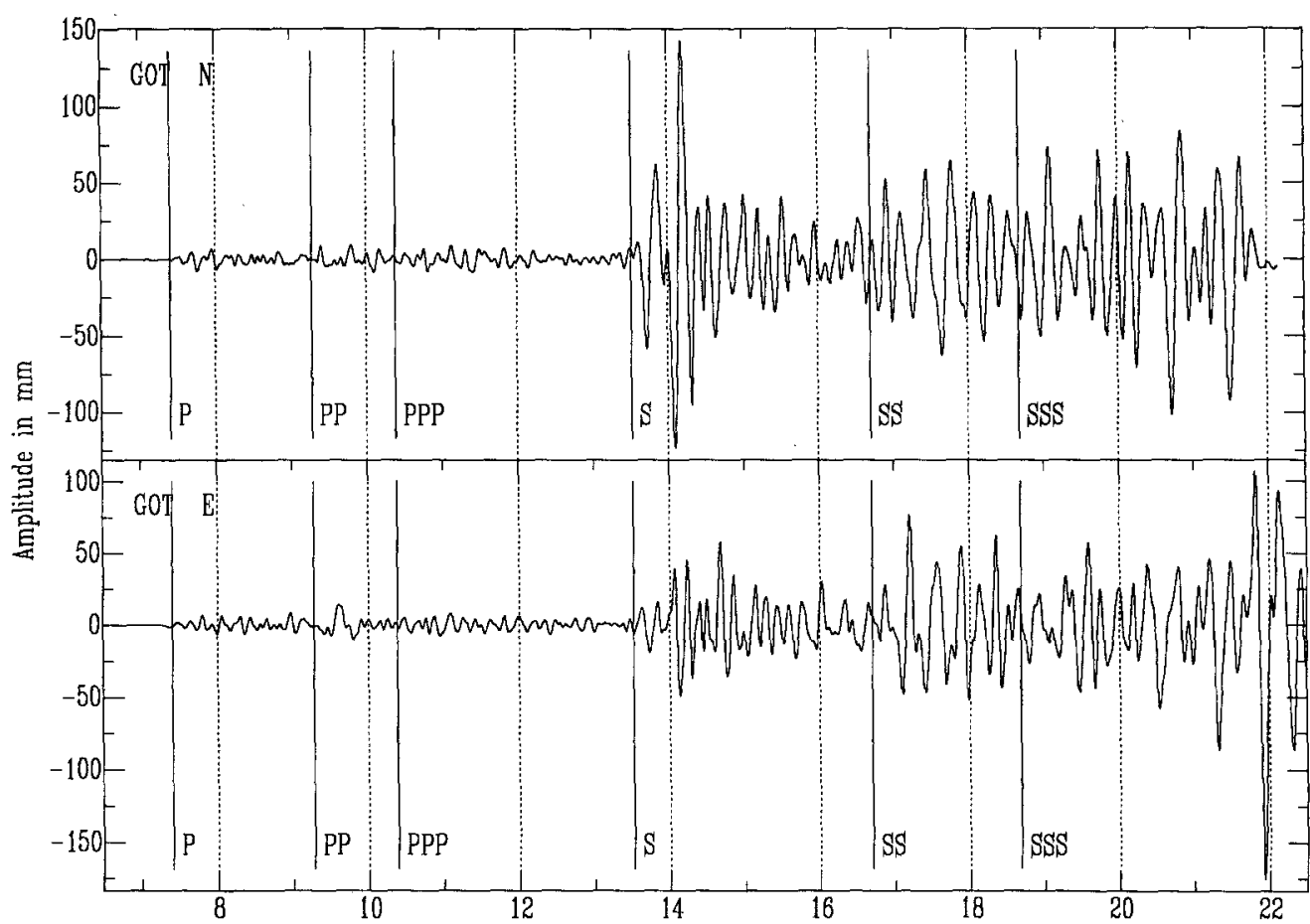

$\times 10+2$

TIME - Seconds $\times 100$

FIG. 7. Digitized 1906 recording at Gottingen, Germany (GOT) after instrument normalization and convolution with the WWSSN long-period response.

refer to seconds after the origin time. There is a close correspondence of observed and predicted arrival times. Figure 8 shows the data from station UPP with a similar format. Both stations show a complicated $S$ wavetrain indicative of complex faulting.

Figure 9 displays the radial component of motion recorded at San Jose, Puerto Rico for both the 1906 San Francisco (top) and 1984 Morgan Hill (bottom) earthquakes. Note that the dominant $S$ wave arrival is very similar in character, even in the overall frequency content. However, the main $1906 \mathrm{~S}$ phase is delayed relative to the Morgan Hill $S$ wave even though the $P$ wave is nearly aligned. This is explained in a later section and is due to source finiteness and complexity for the 1906 earthquake. The amplitude ratio of the $1906 S$ wave compared with that of the Morgan Hill earthquake is nearly a factor of 35.

The complete set of $S$ teleseismic body waves deemed usable for this study are shown in Figure 10. The vertical arrows indicate the predicted $S$ arrival times. The locations of these stations on $S H$ and $S V$ focal spheres for a vertical strike-slip fault striking with the azimuth along the central portion of the 1906 rupture zone $\left(145^{\circ}\right)$ are shown in Figure 11. It is quite apparent that there are limitations with the 1906 data set. The body wave information is predominantly direct $S$ waves and multiples ( $S S$ and $S S S$ ). There is only a single vertical component Wiechert instrument (at Gottingen). It has a good $P$ wave that can be compared with those from other large strike-slip events, but that is the only 


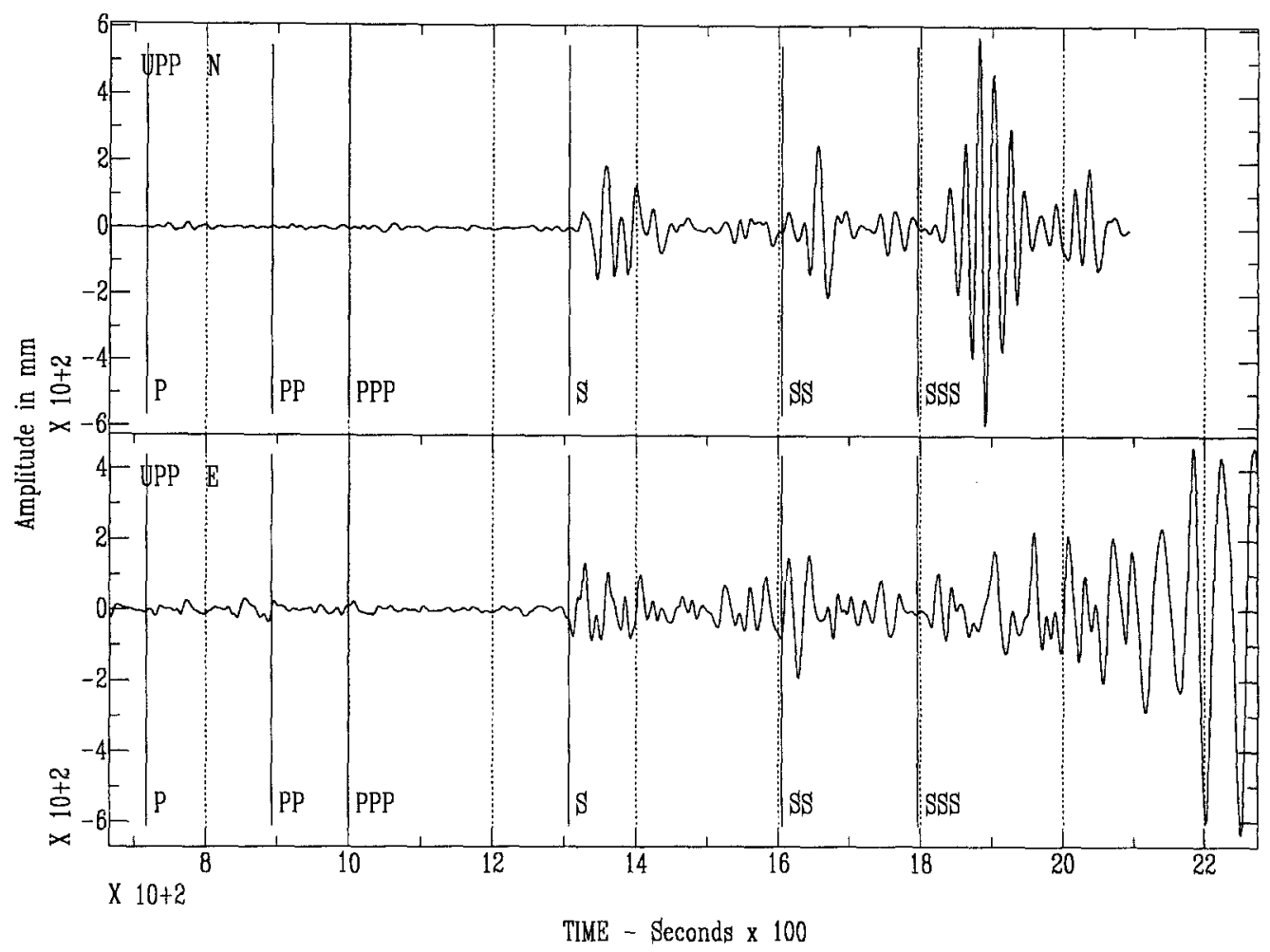

FIG. 8. Digitized 1906 recording at Uppsala, Sweden (UPP) after instrument normalization and convolution with the WWSSN long-period response.

teleseismic vertical recording. Hence, we are basically limited to shear body waves. To compound this, the European stations, for which we have highest quality Wiechert recordings, are nearly $S H$ nodal (Fig. 11). Unfortunately the $S V$ waves are noticeably contaminated by shear-coupled $P L$ waves $(S P L)$ that can often obscure the direct $S$ waveforms on teleseismic seismograms (Baag and Langston, 1985). In order to model these waveforms for the purpose of source determination, it is necessary to address the effects of SPL contamination.

\section{Modern Events for Calibration and Green's Functions}

Because the availability and quality of data for the 1906 earthquake is poor relative to modern standards, a detailed study of modern events is critical for analyzing and placing constraints on the nature of San Francisco data. The events chosen were the Loma Prieta (1989), Morgan Hill (1984), and Coyote Lake (1979) earthquakes. The criteria for selection were that the events must be nearly colocated (as far as teleseismic distances are concerned), have similar focal mechanisms, and have been recorded at modern stations with comparable locations to the historical stations of 1906 . The modern station locations are shown in Figure 5 with shaded triangles; the historical stations are indicated by filled triangles. The European and Asian stations used in this study are shown with an enlarged scale at the right of Figure 5. For stations UPP and GOT the modern and historical stations occupy the same site. In Puerto Rico, stations 


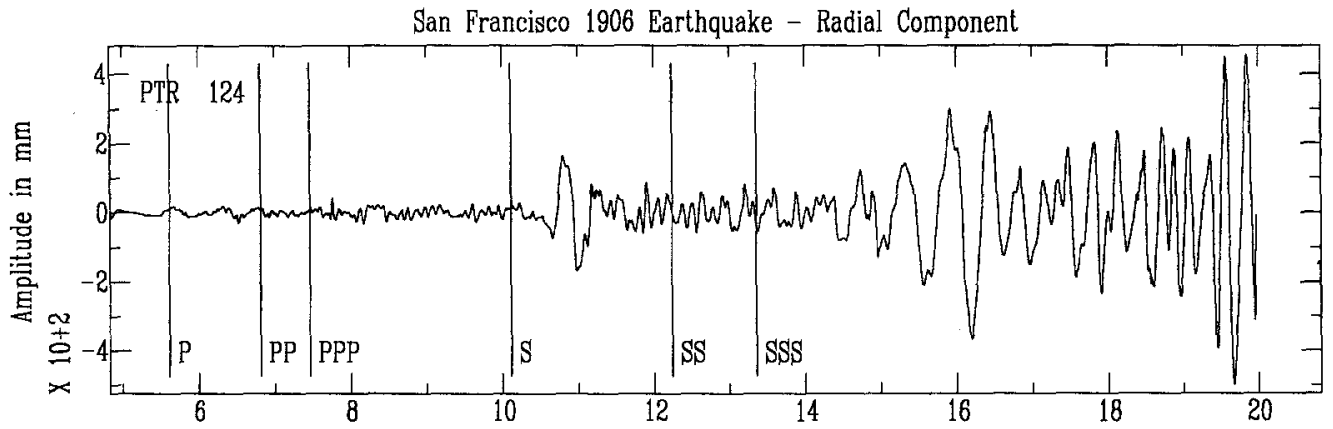

X $10+2$

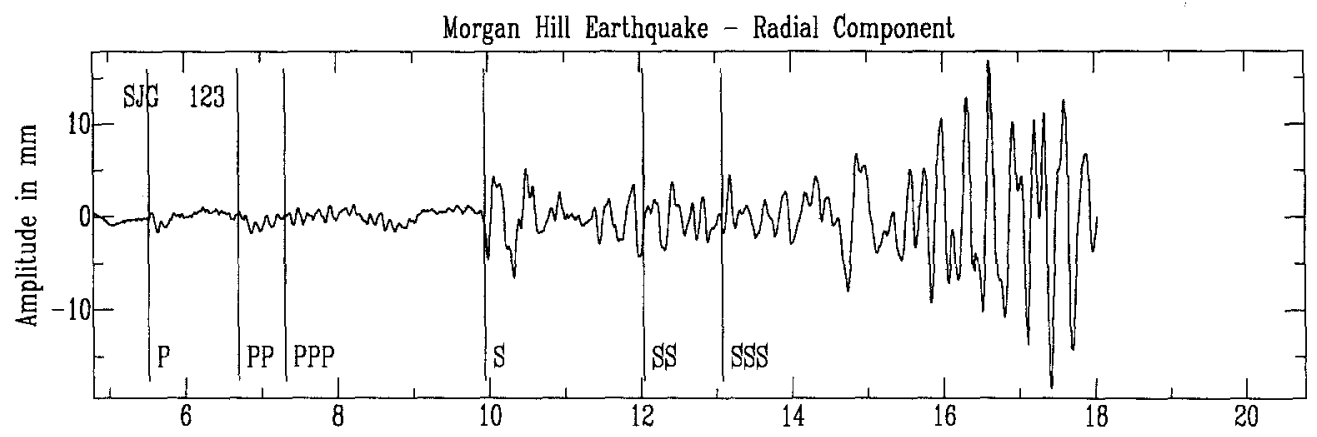

$\times 10+2$

TIME - Seconds x 100

Fig. 9. Comparison of the 1906 San Francisco (top) and 1984 Morgan Hill (bottom) radial waveforms at Puerto Rico.

PTR (historical) and SJG (WWSSN) are very closely situated (Tables 2 and 3). The locations and focal mechanisms of the calibration events are depicted in Figure 1 and the station parameters are given in Table 3. All three calibration events have been well modeled in earlier source studies, so good estimates of source mechanism, seismic moment, time duration, and slip distribution are available in the literature (e.g., Beroza and Spudich, 1988; Ekström, 1984; Hartzell and Heaton, 1986; Liu and Helmberger, 1983; Wald et al., 1991). By analyzing these smaller events at stations close to the ones that recorded 1906, we can estimate the amount and effect of $S P L$ contamination. Unfortunately, there is not always an identical station location for modern and older instruments, and $S P L$ is often quite site specific. This makes it difficult in some cases to quantify the $S P L$ contamination. Ideally, we would like to be able to examine the smaller, calibration events with simple, known source time histories in order to determine the amount of $S P L$ contamination and then empirically include this site response. However, the calibration stations available must be close enough to the station of interest or the site effects may not be representative enough. Unfortunately, there are no usable long-period recordings of the calibration events in the vicinity of the 1906 TAC recording in Mexico City, and the amplitude of that recording is suspect. It is therefore difficult to make use of the TAC recording even though it is at a very desirable azimuth along strike of the San Andreas Fault toward the southeast.

An examination of the Morgan Hill and Coyote Lake shear arrivals demonstrates the importance of receiver complications and $S P L$ waves. The source 
1906 San Francisco Observed S waves

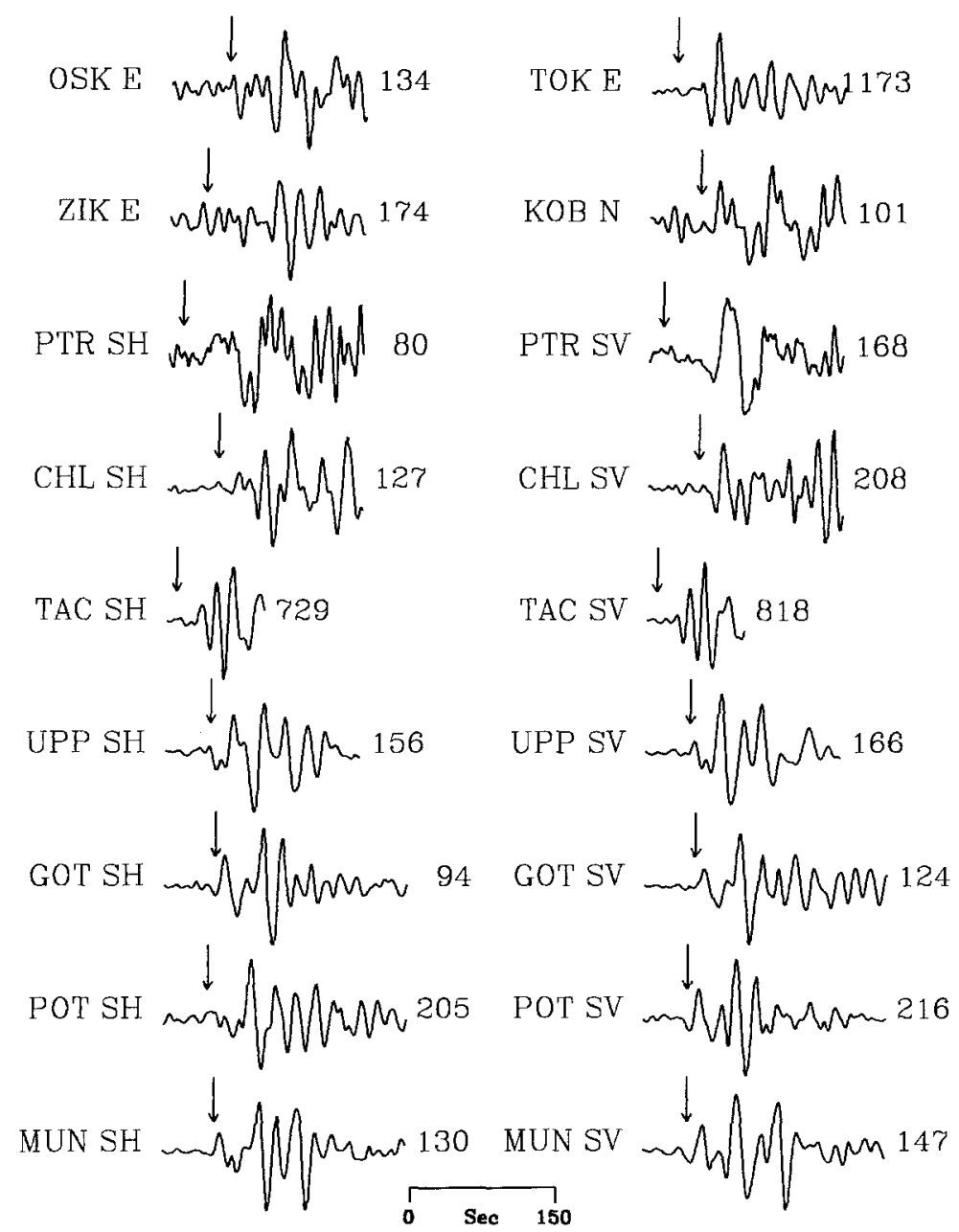

FIG. 10. Available set of teleseismic $S$ waves. The arrows indicate the predicted arrival time of the $S$ wave.

mechanisms are very similar, although the Coyote Lake geometry shows a slight nonvertical dip (see Fig. 1). Hence, we expect the waveforms to be quite compatible. Figure 12 shows the recorded and synthetic $S H$ and $S V$ waveforms at Uppsala, Sweden for both events displaying similarity of the waveforms. Observe that the amplitudes for these recordings are very small (less than 1 $\mathrm{mm}$ on the original paper records), yet the scanning/digitizing system we employ can recover the details remarkably well. The waveform similarity suggests that these magnitude 6 events can be effectively used as Green's functions for a much larger event. They differ only in amplitude, the ratio reflecting the moment ratio of Morgan Hill with respect to Coyote Lake (between 3.5 and 4.5).

Synthetic waveforms were produced for the Morgan Hill earthquake using the finite fault slip distribution of Hartzell and Heaton (1986); for the Coyote Lake simulations the source model of Liu and Helmberger (1983) was employed. As 

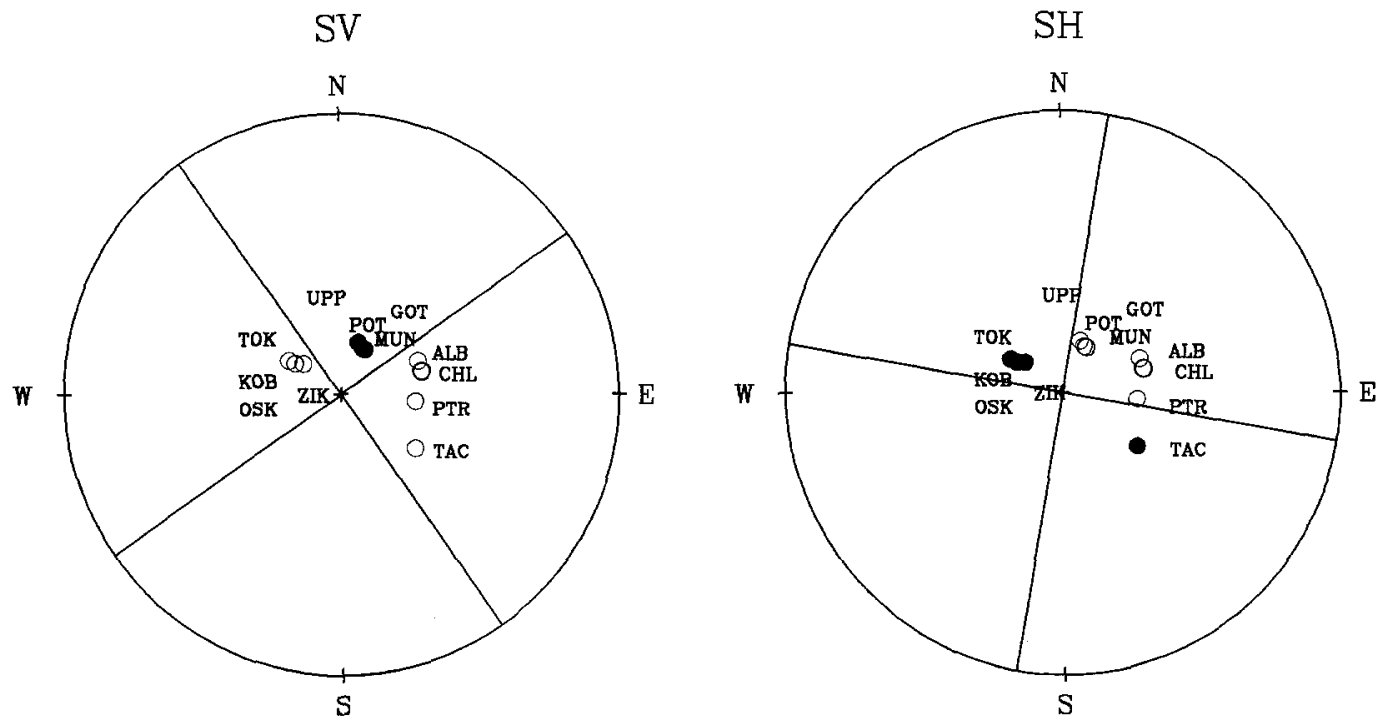

FIG. 11. $S H$ and $S V$ nodal planes for vertical strike-slip on the central portion of the San Andreas Fault. Stations are plotted as a function of azimuth and take-off angle.

TABLE 3

Station Abrreviations and Parameters for Morgan Hill. Distances are with Respect to the EPICENTER DETERMined AT LattTude 37.317 NoRTH AND LoNGITUde 121.682 West.

\begin{tabular}{llcrrrrr}
\hline Station & Location & Latitude & Longitude & $\begin{array}{c}\text { Distance } \\
\text { (Deg.) }\end{array}$ & Azimuth & $\begin{array}{c}\text { Back } \\
\text { Azimuth }\end{array}$ \\
\hline UPP & Uppsala, Sweden & 59.858 & 17.627 & 77.5 & 19.7 & 327.8 \\
MAJO & Matsushiro, Japan & 36.542 & 138.209 & 75.8 & 305.1 & 54.1 \\
RSNY & Adirondack, NY & 44.548 & -74.530 & 35.9 & 63.3 & 275.1 \\
GRFO & Graefenberg, Germany & 49.69 & 11.22 & 83.9 & 28.6 & 324.0 \\
BLA & Blackburg, VA & 37.21 & -80.42 & 32.7 & 77.4 & 283.0 \\
OGD & Ogdensburg, NJ & 41.07 & -74.62 & 36.3 & 69.2 & 279.8 \\
SHK & Shiraki, Japan & 34.530 & 132.678 & 80.6 & 306.3 & 51.1 \\
SJG & San Juan, P.R. & 18.112 & -66.150 & 52.0 & 95.7 & 303.5 \\
STU & Stuttgart, Germany & 48.771 & 9.193 & 83.8 & 30.2 & 322.7 \\
\hline
\end{tabular}

can be seen in the synthetic waveforms in Figure 12, the source contribution to the waveform complexity is negligible when viewed through the long-period WWSSN response (peaked at $15 \mathrm{sec}$ period) because the entire duration of either event is less than $7 \mathrm{sec}$. The synthetic waveforms predict only the simple first $S$-wave arrival, although the observations indicate the arrival of $S c S$, approximately $26 \mathrm{sec}$ after the direct $S$-wave arrival, as indicated with arrows. Theoretically, $S c S$ should be less than half the size of $S$. It should have the same sign as direct $S H$ and opposite to that of direct $S V$ assuming a strike-slip orientation. These features are not obvious in these observed waveforms nor at other European stations. Thus, this complexity in the $S$ waves is not easily modeled. The large, later arrivals on the $S V$ component is composed of $S P L$ energy. In order to investigate the later part of the shear wave train for the 


\section{Uppsala, Sweden}

SH
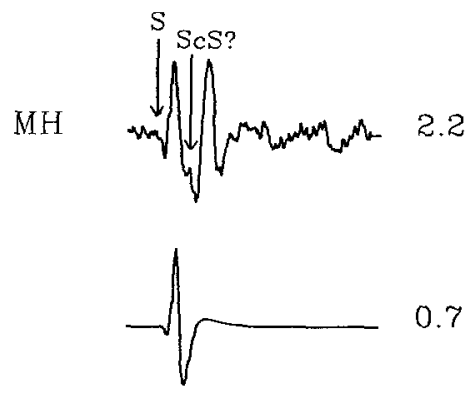

0.7
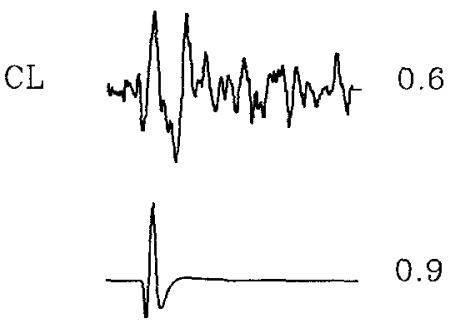

0.9
SV
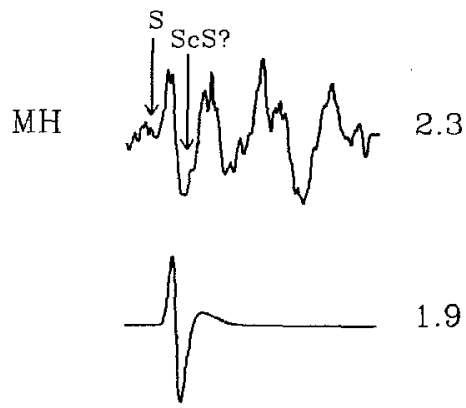

$\mathrm{CL}$
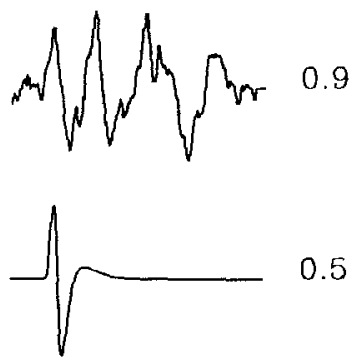

FIG. 12. WWSSN long-period recordings for calibration events Morgan Hill (MH) and Coyote Lake (CL) showing $S P L$ contamination. Observed recordings are above the synthetics seismograms. Arrows indicate arrival times of direct $S$ and $S c S$.

1906 records, it is critical that we include these later contributions. Otherwise, we may not be able to attribute later arrivals in the $S$ wavetrain to complexities of the source rupture process. Fortunately, these arrivals can be effectively included with the use of these recordings as empirical Green's functions.

\section{SuRFACE Wave ANaLysis}

Spectral ratios were computed as a function of frequency by dividing the Fourier transformed waveforms from 1906 stations by the transform of the data from the corresponding Morgan Hill station. The advantage of computing spectral ratios in this manner rather than theoretically correcting for radiation pattern is that the site effects are best accounted for empirically. Only stations ALB, PTR, and UPP had both digitizable 1906 surface waves and data recorded at the corresponding modern stations. The average spectral ratio at $50 \mathrm{sec}$ was approximately 120. Assuming the 1984 Morgan Hill earthquake had a moment of approximately $2.5 \times 10^{25}$ dyne-cm, this requires a moment of $3.0 \times 10^{27}$ dyne-cm for the 1906 earthquake. At a period of $100 \mathrm{sec}$, the ratio was nearly 180 , yielding a moment of $4.5 \times 10^{27}$ dyne-cm $\left(M_{W}=7.7\right)$. These values are quite similar to the estimates of $3.2 \times 10^{27}$ dyne-cm at $50 \mathrm{sec}$ and $4.7 \times 10^{27}$ dyne-cm at $100 \mathrm{sec}$ determined by Thatcher (1975) from Love and Rayleigh wave spectral amplitudes, although a different set of stations (UPP, GOT, and ZIK) were used in that study. 


\section{Body Wave Analysis}

Examination of the 1906 shear wave data (Fig. 10) indicates that there is a small, initial $S$-wave arrival at the time of the predicted $S$-wave arrival (shown with the vertical arrows) followed by a dominant, larger phase about 30 to 40 sec later. There is a clear time difference of these two arrivals as a function of azimuth ranging from $36 \mathrm{sec}$ at KOB and $39 \mathrm{sec}$ at GOT to nearly $45 \mathrm{sec}$ at PTR. As will be further discussed, this is consistent with two sources separated along the strike of the San Andreas Fault.

\section{Amplitude Comparisons with Calibration Events}

First order results were obtained by simply making comparisons of teleseismic waveform complexity and amplitudes of the 1906 recordings with the Coyote Lake, Morgan Hill, and Loma Prieta $S$ waves. The durations of the 1906 teleseismic $S$ waves are relatively short and the complexity of the waveforms is not great (Fig. 10), considering the rupture length was at least $300 \mathrm{~km}$. On average, the largest $1906 S$ waves are about 3 to 5 times larger than the largest Loma Prieta $S$ waves as recorded at the same stations (GOT and UPP). Neglecting the differences in source radiation pattern, this requires an excitation of 5 to 15 sec energy several times that of Loma Prieta along some limited portion of the 1906 rupture. Comparing the 1906 and Morgan Hill $S$ waves gives an average amplitude ratio of about 40; the ratio for Coyote Lake is approximately 135 . With the seismic moments determined for the calibration events we can estimate the size of the dominant asperity of the 1906 earthquake by assuming the asperity rupture duration is comparable to that total duration of the calibration events. This assumption proves valid and is discussed in the next section. These estimated seismic moment values are summarized in Table 4. This, of course, is not the total moment for 1906, just an estimate of the portion of the fault responsible for producing 5 to $20 \mathrm{sec}$ body waves.

\section{Forward Modeling}

A straight forward approach to modeling the 1906 recordings is to use the Morgan Hill $S$-wave recordings as Green's functions and to lag and sum them to produce 1906 simulations. A previous example of the use of empirical summation for teleseismic waveform modeling is given by Bent et al. (1989) for the 1987 Superstition Hills, California earthquake. Here we are fortunate to have a subevent (Morgan Hill) with the appropriate source mechanism and a known seismic moment. The radiation pattern is nearly that of the 1906 rupture along the central portion of the San Andreas Fault (Fig. 1). The Coyote Lake earthquake is not used for an empirical simulation because its mechanism is slightly

TABLE 4

Estimates of THE MAIN 1906 AsperiTy fRom CoMpaRison with CALIBRATION Event AMPLITUdeis. SEE TEXT FOR DeTAILS.

\begin{tabular}{cccc}
$\begin{array}{c}\text { Calibration } \\
\text { Earthquake }\end{array}$ & $\begin{array}{c}\text { Seismic Moment } \\
\left(\times 10^{25} \text { dyne-cm }\right)\end{array}$ & $\begin{array}{c}\text { Scaling Factor } \\
(\mathrm{N})\end{array}$ & $\begin{array}{c}1906 \text { Asperity Moment } \\
\left(\times 10^{27} \text { dyne-cm }\right)\end{array}$ \\
\hline Loma Prieta & 30 & 3 & 0.9 \\
Morgan Hill & 2.5 & 40 & 1.0 \\
Coyote Lake & 0.5 & 135 & 0.8 \\
\hline
\end{tabular}


different from the 1906, and perhaps more important, its seismic moment was about 3 to 4 times smaller than that of the Morgan Hill event, and thus has fewer well-recorded signals at teleseismic distances. Loma Prieta was very well recorded teleseismically, but the faulting geometry is significantly different from vertical strike-slip (Fig. 1) and therefore cannot be used without a correction for the radiation pattern and the associated (and unknown) effect on the $S P L$ signals. Although appropriate for the central part of the 1906 rupture zone, the Morgan Hill mechanism is slightly discrepant in strike for subevents along the northwest and southeast sections. It is also possible that a substantial portion of oblique thrusting occurred in the Loma Prieta segment of the fault, in which case the Morgan Hill Green's functions are not appropriate.

In a forward modeling sense, we determine the best locations and amplitudes for subevents along the trend of the San Andreas Fault in order to fit the recorded 1906 teleseismic waveforms and amplitudes. We use approximately $200 \mathrm{sec}$ of the Morgan Hill $S$-wave records as empirical Green's functions. By assuming a constant rupture velocity $V_{r}$ of $2.7 \mathrm{~km} / \mathrm{sec}$, we compute the delay at each station, $\Delta t_{i}$, for a number of subevent positions along strike within the onshore rupture zone. For a distance $D$ along strike from the epicenter

$$
\Delta t_{i}=\frac{D}{V_{r}}-D \cos \left(\phi_{0}-\phi\right) P
$$

where $V_{r}$ is the assumed rupture velocity, $\phi_{0}$ is the station azimuth, $\phi$ is the fault strike, and $P$ is the ray parameter. We then determined the best multiplicative amplitude scaling factor, $N$, to weight each subfault Green's function by in order to obtain the observed 1906 amplitudes.

Using the relationship equating seismic moment to fault slip, $M_{0}=\mu A \bar{u}$, where $\mu$ is the rigidity, $A$ is the area, and $\bar{u}$ is the average dislocation, we can estimate the average slip and the area over which it occurred for the Morgan Hill earthquake. Based on the strong motion inversion models of Hartzell and Heaton (1986) and Beroza and Spudich (1988), we assume a rupture approximately $12 \mathrm{~km}$ in length and $10 \mathrm{~km}$ deep having a seismic moment of $2.5 \times 10^{25}$ dyne-cm. Using $\mu=3.2 \times 10^{11}$ dyne $/ \mathrm{cm}^{2}$, based on their crustal models, we find the average slip to be about $65 \mathrm{~cm}$. This allows us to relate the scale factor, $N$, for the number of Morgan Hill Green's functions to the approximate slip on the fault we allow it to represent.

Initially, we computed the teleseismic body wave signal based on the geodetic slip model of Thatcher (1975). Using the above conversion from a single Morgan Hill Green's function to slip, we summed the appropriate number of Green's functions to approximate the geodetic slip model. The geodetic model of Thatcher (1975) is shown as a function of position along strike with filled triangles in the bottom portion of Figure 13. The observed surface offset, also from Thatcher (1975), is also shown with filled squares. Note that the distance corresponds to kilometers from the epicenter south of San Francisco and increases along strike to the northwest. Atop Figure 13 is a schematic diagram of the fault slip model used to approximate the geodetic slip. The subfault weights correspond to the multiplicative weighting factor $N$. There are 28 subfaults, numbered from northwest to southeast beginning at Point Arena. The hypocenter, indicated with a star, is located in subfault 22 . The area of each subfault corresponds to 


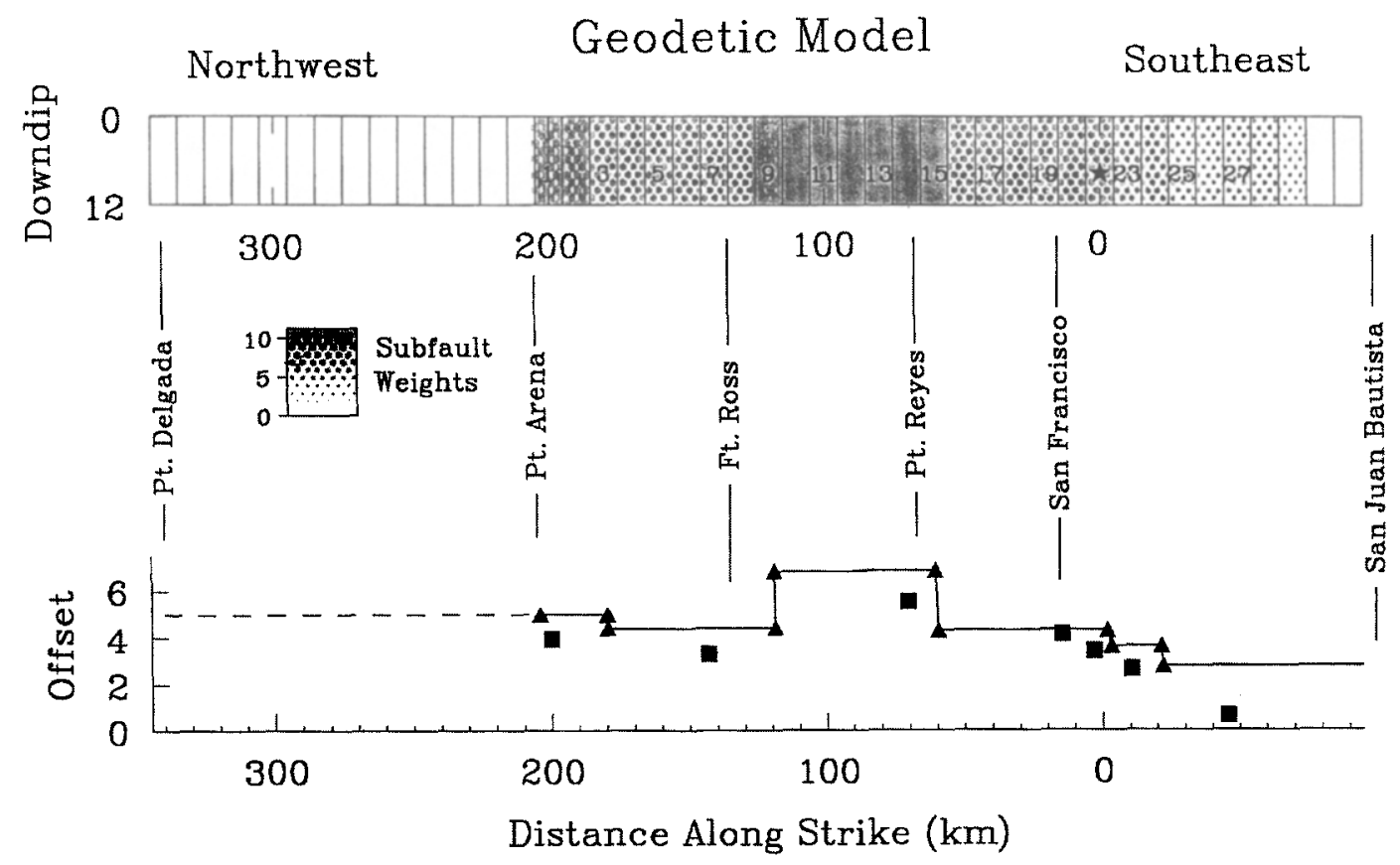

FIG. 13. Schematic of the geodetic fault model (top) showing subfault layout. The numbered subfaults were allowed to contribute to the teleseismic signal. Shading is proportional to fault slip through the weighting factor $N$ as shown by the scale bar (see text). The distance given is along strike from the hypocenter (star in subfault No. 22).

the effective rupture area of the Morgan Hill subevent. Note that we did not include a model for the offshore region (205 to $340 \mathrm{~km}$ ) in our simulations. As described above, there is little evidence in the latter part of the teleseismic records of substantial 5 to 20 energy release from this portion of the fault.

Figure 14 shows the observed $1906 S$ waves modeled with the corresponding $S$ waves computed with the Morgan Hill empirical Green's function scaled to the geodetic slip. For each component, the top trace is the observation, the middle trace is the synthetic, and the third trace shows an overlay of the two for comparison, the synthetic being distinguished with a dashed line. The overall amplitudes of the synthetics for the geodetic model are about $50 \%$ of the observed amplitudes, suggesting the need for more intense slip variations. In general there is marginal agreement with the data for some features of the waveforms, although the timing of the largest arrival is poor and does not fit the data. Furthermore, the synthetic traces often are longer period than the data.

Next, in a forward modeling sense, we determined the best simple, rupture model in order to satisfy the observation of the relatively small, initial phase at the $S$-wave arrival time and the larger arrival 35 to 45 sec later, seen in Figure 10. The best model found by trial-and-error came from a relatively simple summation consisting of two regions of strong radiation separated in time by an average of about $38 \mathrm{sec}$. The relative weighting factor $N$ was determined to be about 14 for the hypocentral subfault and 30 for subfault 10. This corresponds to about $110 \mathrm{~km}$ of separation between the two major regions of strong radiation at these periods (about 5 to $20 \mathrm{sec}$ ), placing the largest between Point Reyes and Fort Ross. 

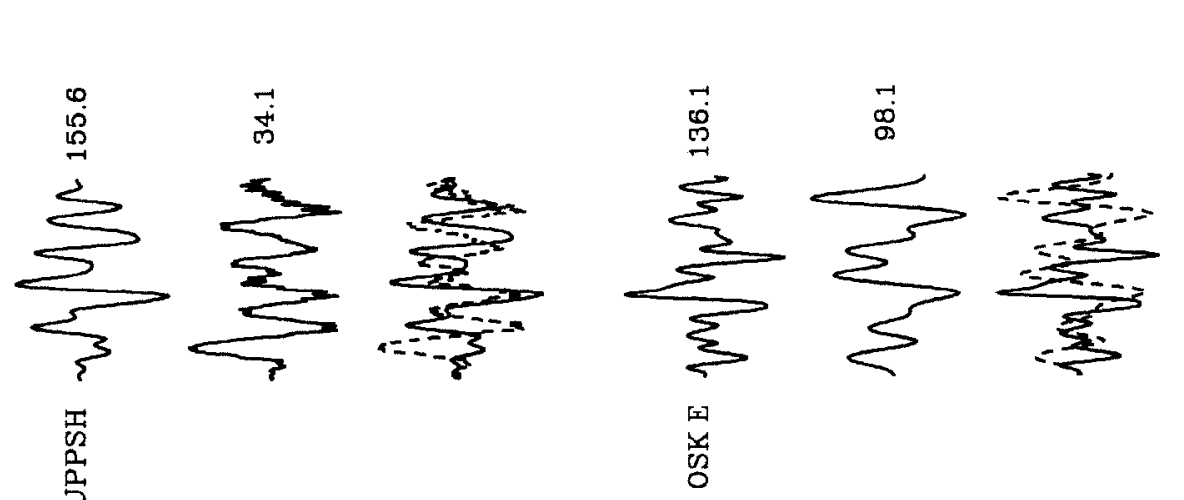

咅

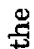

萝

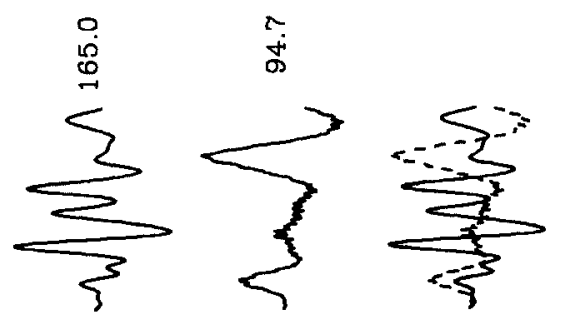

0
0
0
0
0
0
0
0
0
0
0
0
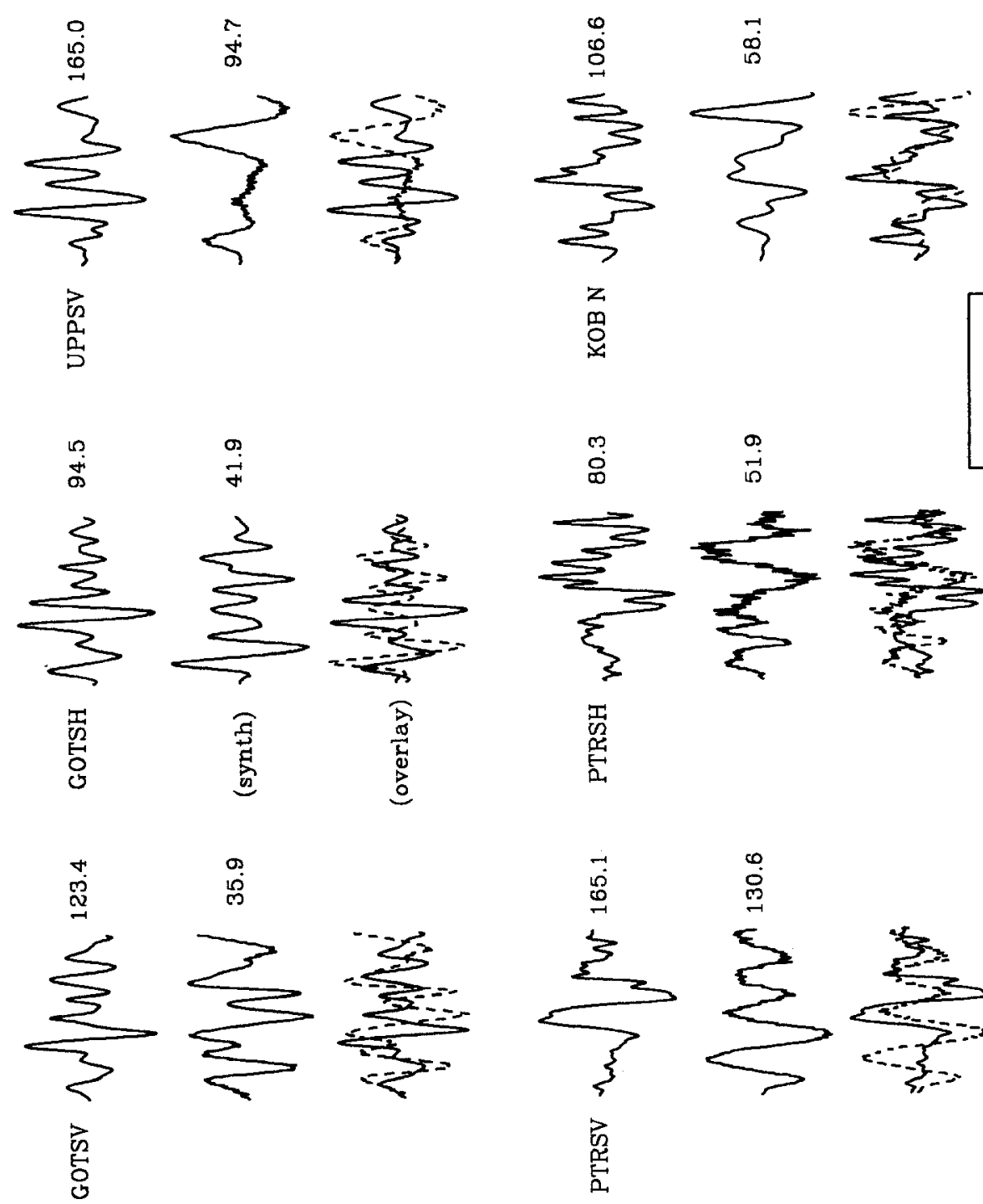

䌟

怘<smiles>[3H]</smiles>
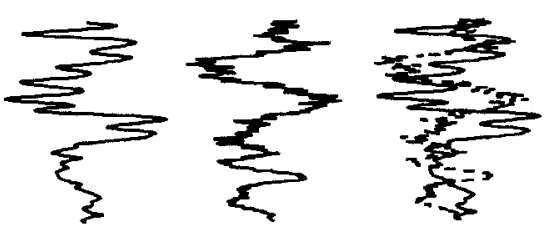

焉

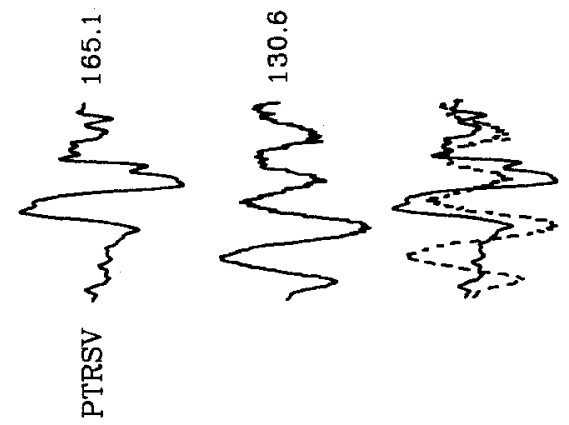




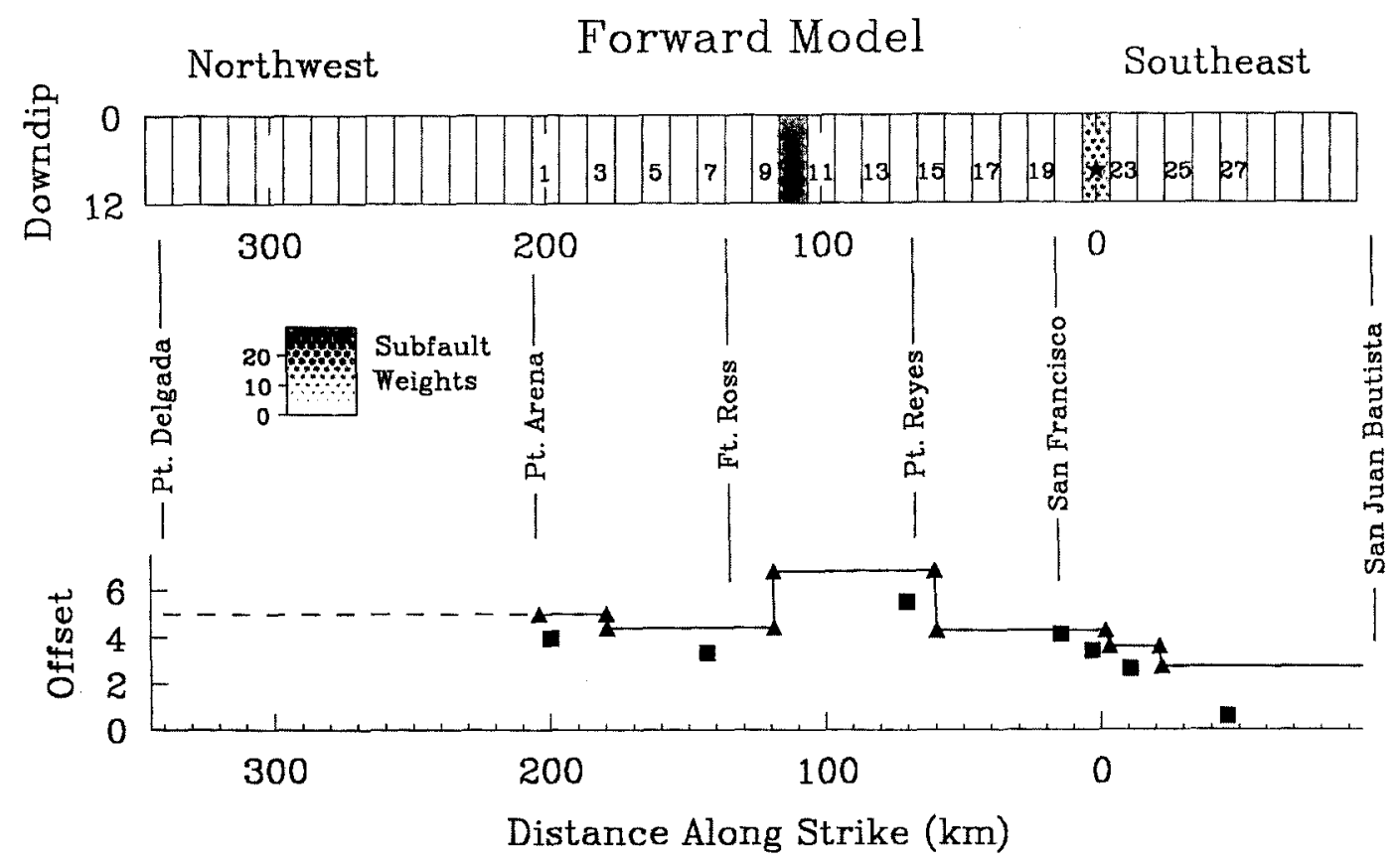

FIG. 15. Schematic of the forward model results. The bottom portion of the figure is the same as in Figure 13.

In short, we see that the teleseismics can be explained by about 14 Morgan Hill events summed near the epicenter, a region where the amount of slip changes quite abruptly according to surface offset, and about 30 Morgan Hill events concentrated at about $110 \mathrm{~km}$ from the epicenter, where the geodetic and surface slip is near its greatest (Fig. 15). The synthetics from the empirical summation are shown in Fig. 16. A good portion of the shear wave train is fit at most stations.

\section{Source Inversion}

Solving for the location and scale factor of the subevents to best satisfy the timing and amplitude of the observed waveforms can be set up as a least squares inversion. Again, we assume a fixed rupture velocity of $2.7 \mathrm{~km} / \mathrm{sec}$, and solve for the over-determined system of linear equations, $A x \cong b$, using linear least squares to determine $x$, the solution vector of subfault weights. Here, the matrix $A$ consists of synthetics (empirical Green's functions) of equally weighted subfault responses strung end to end, each lagged according to its rupture and travel time delay and $b$ is the data vector.

The result of the inversion, shown in Figure 17, is nearly that of the forward estimation also showing two main regions of radiation, although several more subfaults contribute to the solution. On the bottom of Figure 17 we show the corresponding slip values determined from the inversion (open circles), along with an estimate of the uncertainty in these values (error bars). The uncertainty in the subfault slip was estimated from the covariance of the model parameters because of a variance in the data (for details, see Hartzell and Iida, 1990; Olson and Apsel, 1982); it does not address errors due to assumptions in the fault 

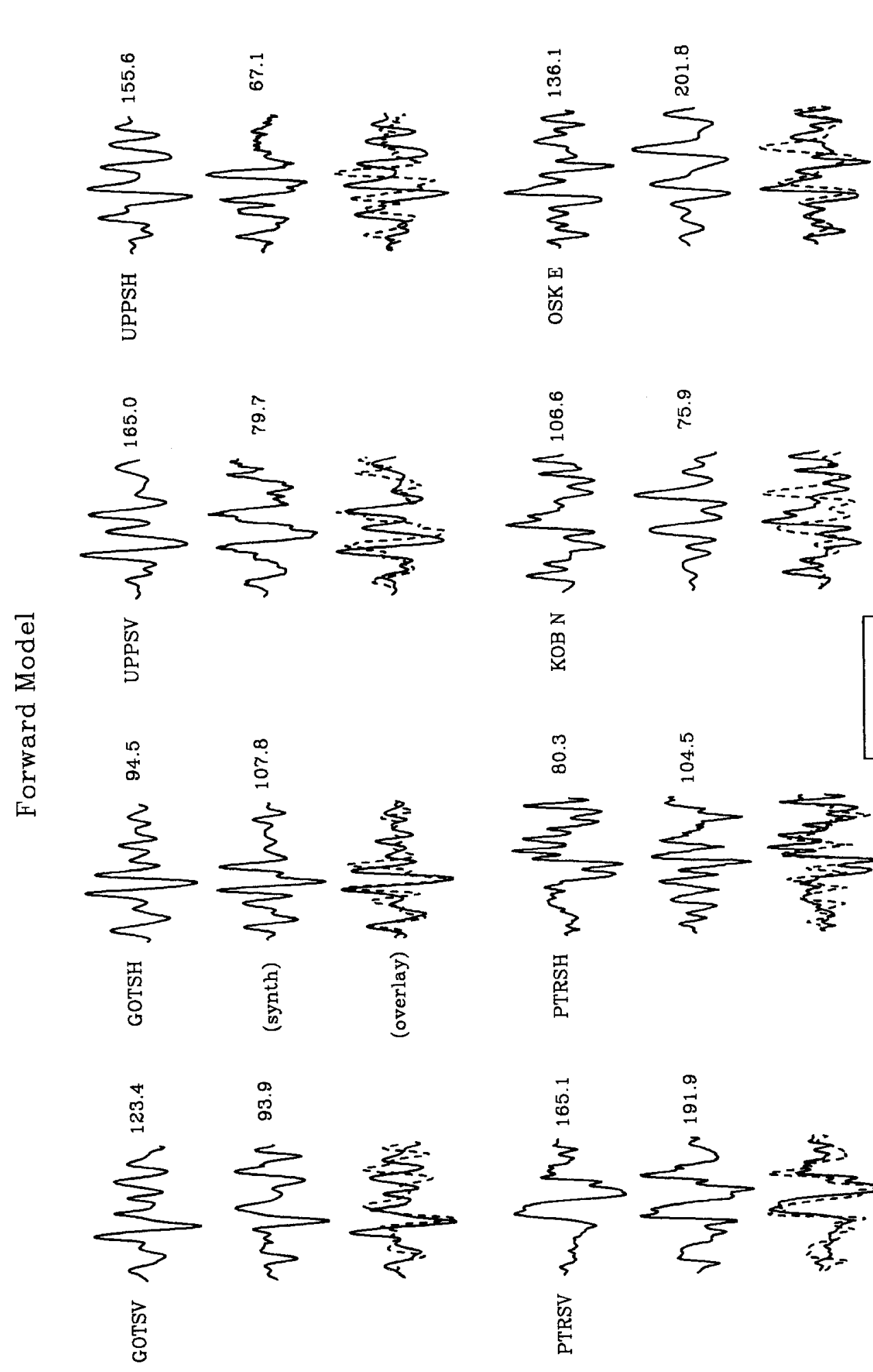

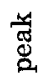
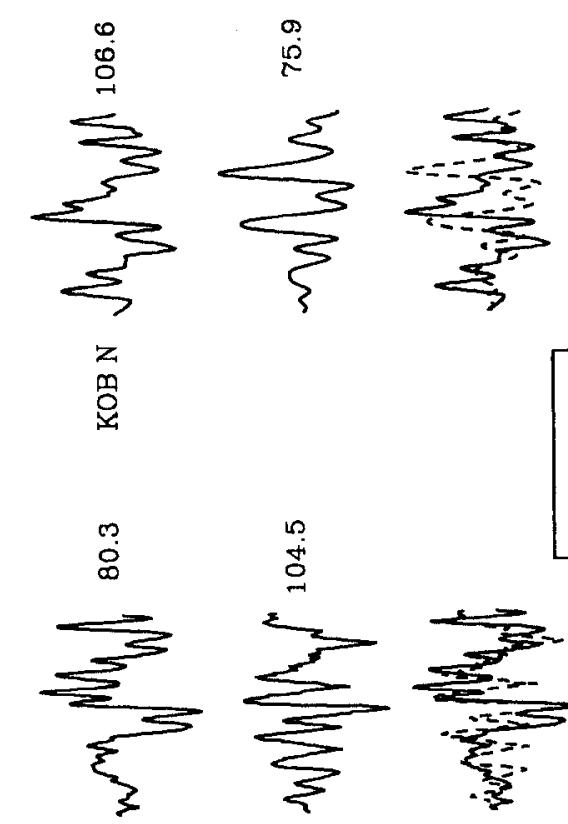

g

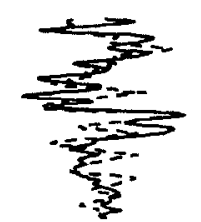




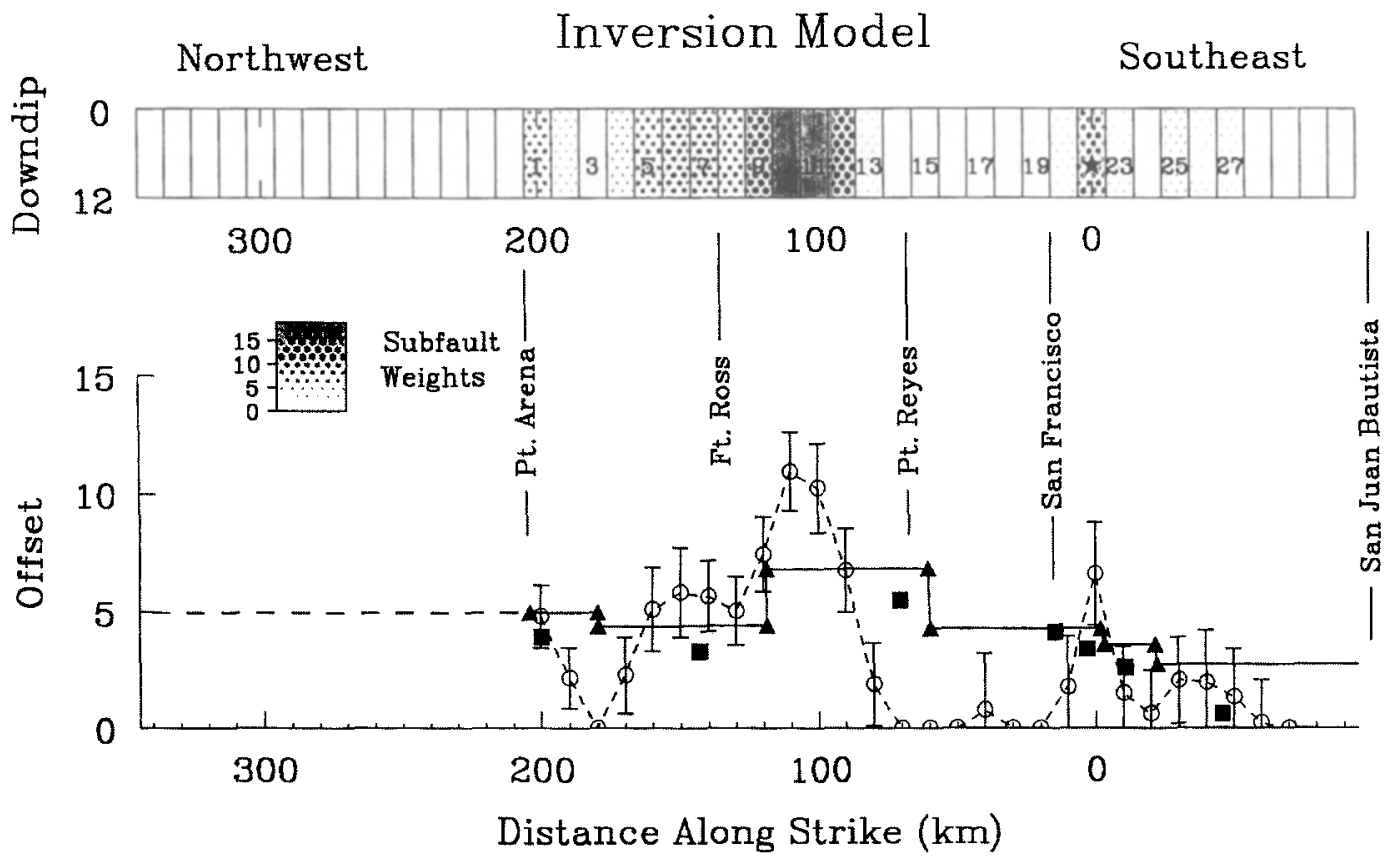

Fig. 17. Schematic of the inverse model results. In the lower part of the figure, inversion slip values (circles) with corresponding uncertainty estimates (error bars) are shown. The geodetic slip is shown with filled triangles connected with a line, and the surface offset is given with filled squares (Thatcher, 1975).

rupture model parameterization. The waveform fits are given in Figure 18. In a formal sense, the solution from the inversion has a slightly lower misfit to the data, but there are features in waveforms produced by the forward modeling which are more favorable.

As shown in the forward and inverse models, the arrival in the data corresponding to the largest subsource can be fit well with a very limited dimension along strike. In order to place constraints on the dimensions of the region of large source radiation near subfault 10 , we performed a summation of empirical Green's functions lagged in space over various linear dimensions. We found that as the along-strike length increases above about $40 \mathrm{~km}$, the match of the details of the waveforms at the best modeled stations is degraded (Fig. 19). With an extended source dimension of $55 \mathrm{~km}$, the higher frequency content of the data at station GOT, the most reliable station, is difficult to simulate.

\section{Strong Motion Estimations}

In a recent study, Wald et al. (1992) found that the source model of the 1989 Loma Prieta earthquake determined from inversion of teleseismic data alone was sufficient for predicting many of the features of observed strong motions. They determined that even with a limited overlap in the bandwidths of the two data sets, the general asperity characteristics determined at longer periods were consistent with the slip distribution needed to simulate the higherfrequency ground motions.

In the previous section, we found that the amplitudes and frequency content of the teleseismic data for 1906 allowed us to roughly constrain the scale length 


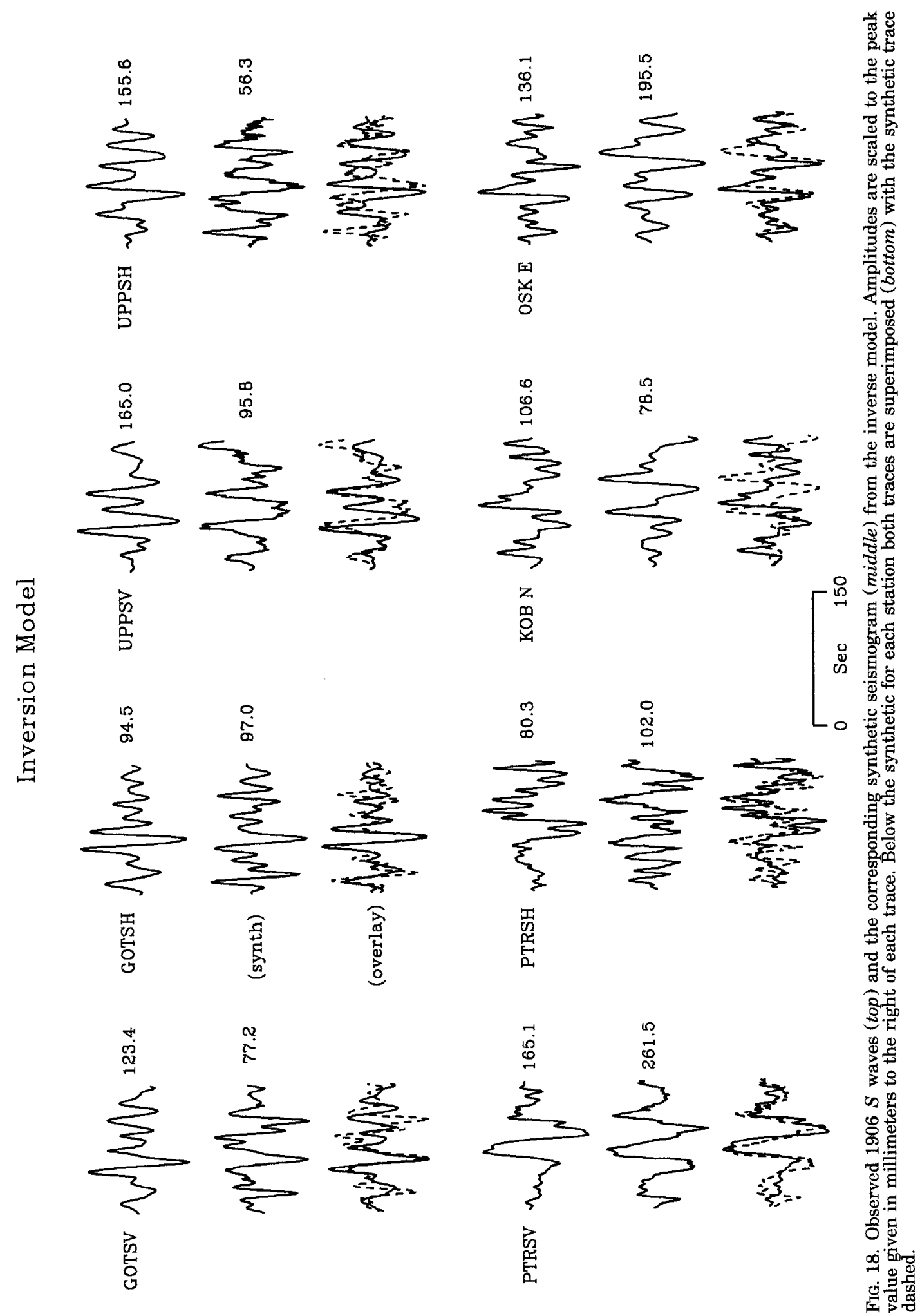


1906 Observations vs. Morgan Hill Empirical Summation
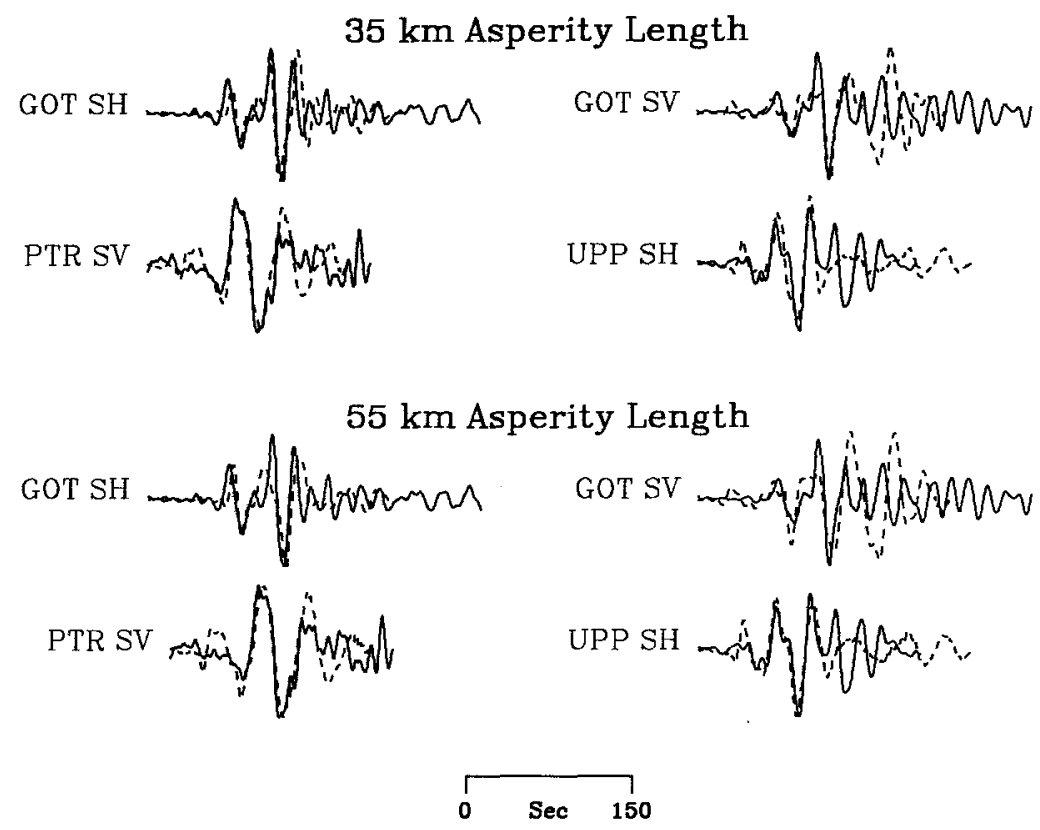

FIG. 19. Comparison of forward model synthetics for empirical summation of the largest asperity with source spread out over $35 \mathrm{~km}(t o p)$ and $55 \mathrm{~km}$ (bottom).

of the largest asperity to be less than $40 \mathrm{~km}$. Slightly larger dimensions are not ruled out, but for the purpose of this estimate of strong motions for the 1906 earthquake, we use a compact asperity size to produce relatively conservative strong motions predictions. Having a rough constraint on the largest asperity (size and magnitude) we produced synthetic ground velocities as follows. For purposes of comparison with the recent, abundant Loma Prieta strong motion data set, we "moved" the largest 1906 asperity into the Loma Prieta region. In this way, we could compare our simulations with observations from a $M_{W}=6.9$ at the same distances and station geometries. We then took the Loma Prieta slip model of Wald et al. (1991) and by rotating the model fault to a vertical plane and constraining the dislocation to be pure right-lateral strike-slip, we approximated rupture along the San Andreas Fault. The Loma Prieta rupture was bilateral, but we use a northwest propagating unilateral rupture to simulate the 1906 model determined from the teleseismic data.

To be consistent with the average depth of significant slip from other strong motion waveform inversions of California vertical strike-slip earthquakes (Hartzell and Heaton, 1983; Hartzell and Heaton, 1986; Beroza and Spudich, 1988; Wald et al., 1990) we needed to decrease the asperity depth relative to the Loma Prieta model. This was done by bringing the top of the fault to within 0.5 $\mathrm{km}$ of the surface and translating the slip (shown in Figure 20, top) $5 \mathrm{~km}$ closer to the top of the fault than the Loma Prieta slip model.

To simulate the 1906 asperity, we spatially shifted and summed three Loma Prieta slip distributions (Fig. 20, bottom) to preserve the amplitude of slip determined from the forward empirical summation model keeping the dimen- 

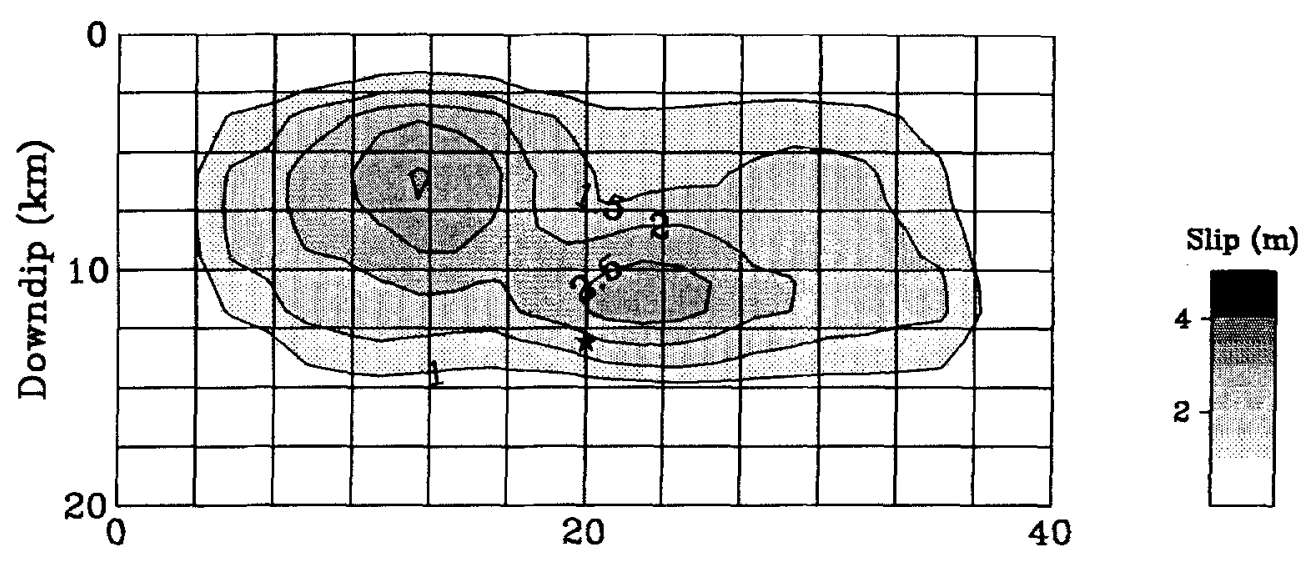

1906 SAN FRANCISCO MAIN ASPERITY ESTIMATE
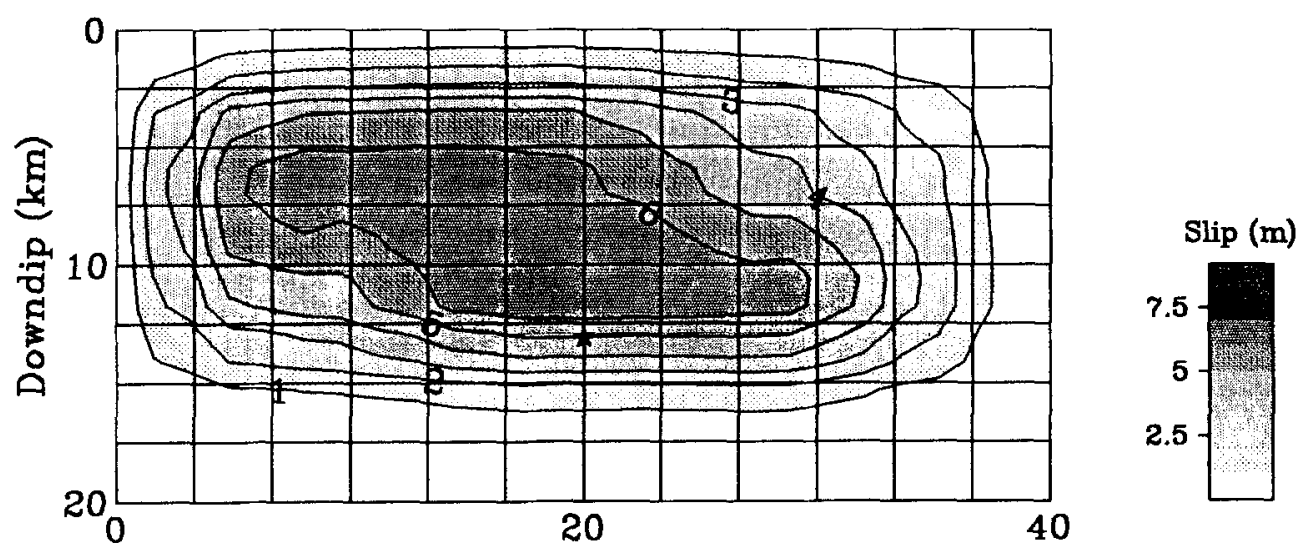

FIG. 20. Slip distribution of Wald et al. (1991) for the Loma Prieta earthquake modified by shallowing the slip and rotating the dip to vertical and the rake to pure strike-slip (top). Bottom slip model is the scaled-up version of Loma Prieta used to simulate the main 1906 asperity obtained from spatial lagging.

sion in line with the $35-\mathrm{km}$ length used to best model the 1906 body waves. Ground motion velocity estimates were made with the finite fault ground motion techniques used in Wald et al. (1991), with synthetic Green's functions appropriate for the Loma Prieta region. The frequency bandwidth of the simulations is from 0.0 to $1.0 \mathrm{~Hz}$.

Although many well-studied earthquakes require very short slip durations (Heaton, 1990), there have been no studies of strike-slip earthquakes of this magnitude with the strong motion recordings necessary to constrain the local slip duration. Heaton (1990) points out that the duration of slip for the 1985 Michoacan earthquake $\left(M_{S}=8.5\right)$ was on the order of 5 sec as indicated from near-field displacements obtained from twice integrated accelerograms. However, the tectonic environment was that of subduction thrusting, and the fault 
aspect ratio was quite different from that of the 1906 earthquake. Consider that for a rupture length of $430 \mathrm{~km}$ and a fault width of 10 to $15 \mathrm{~km}$, the aspect ratio for the 1906 rupture was between about 30 and 45 to 1 , nearly a line source. For earthquakes in the tectonic regime more similar to the northern San Andreas Fault, the slip durations are observed to be very short. For example, recent eyewitness observations of ground rupture during the 1990 Philippines earthquake $\left(M_{S}=7.8\right)$ suggest that the slip duration was less than about $1 \mathrm{sec}$ (T. Nakata, personal communication, 1991), yet the displacement was 3 to $4 \mathrm{~m}$. Furthermore, Wald et al. (1991) found that the majority of slip during the Loma Prieta earthquake occurred in less than 1 sec over most of the fault plane and less than 2 sec everywhere else. From these observations, we assumed a 4-sec rise time for the 1906 slip. However, the derivative of the actual slip function is not a simple triangle, but rather, a time expanded version of the Loma Prieta slip model determined by Wald et al. (1991). The Loma Prieta slip function has three time windows, each 0.7 -sec triangles overlapping by $0.1 \mathrm{sec}$. On average, the first window contributes half the slip, and the second and third each contain $25 \%$ of the slip, but these values change slightly as a function of position on the fault. For the 1906 ground motion simulations, we carry through the spatial rise time variations determined for the Loma Prieta earthquake from the strongmotion data, but use three time windows each $1.4 \mathrm{sec}$ long for a total duration of $4.2 \mathrm{sec}$. We also tested the dependence on rise time by computing synthetic ground motions for longer and shorter total rise times.

Initially, we computed ground motions for the top model on Figure 20 to compare with the simulated ground motions (Wald et al., 1992) of the Loma Prieta earthquake. This simply allows us to compare the ground motions for a deep, oblique-slip event with that of vertical strike-slip. The comparison of peak ground velocities plotted as a function of distance is shown in Figure 21z. The distance, $r_{0}$, is defined as in Joyner and Boore (1988) as the shortest distance (kilometers) from the recording site to the vertical projection of the fault rupture on the surface of the earth. Solid circles denote the Loma Prieta simulations and the shaded circles represent the vertical strike-slip modified model results. The overall amplitudes are slightly higher for the vertical strike-slip case. Considering the source rupture model is identical in all other aspects, differences in the resulting ground motions can be attributed to the combined effects of change in rake and source depth.

In general, vertical strike-slip model predicts slightly larger velocities, especially on tangential components at near-fault stations. The vertical components are slightly smaller because of the radiation pattern. Also plotted as a dashed line is the attenuation relationship of Joyner and Boore (1988) for peak ground velocity:

$$
\begin{gathered}
\log y=a+b(M-6)+c(M-6)^{2}+d \log r+k r+s \\
5.0 \leqq M \leqq 7.7
\end{gathered}
$$

where constants $a=2.17, b=0.49, c=0.0, d=-1.0, k=-0.0026, s=0.17$ and

$$
r=\sqrt{r_{0}^{2}+h^{2}}
$$


Loma Prieta Vs. Loma Prieta VSS
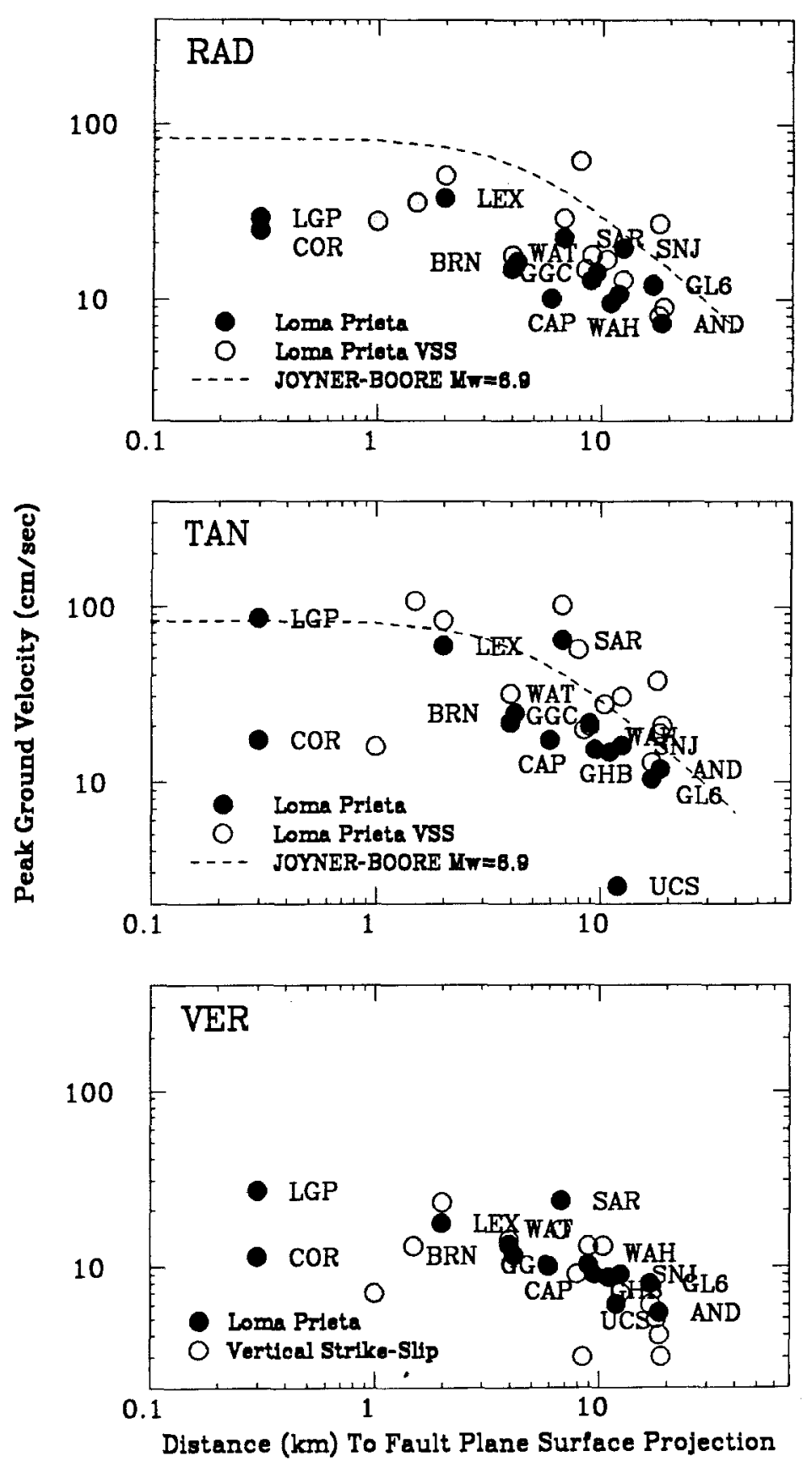

FIG. 21. Radial (top), tangential (middle), and vertical (bottom) peak ground velocities for simulations of the Loma Prieta ground motions (solid circles) compared with the modified vertical strike-slip Loma Prieta model (shaded circles). The attenuation relationship of Joyner and Boore (1988) is given with the dashed line for $M_{w}=6.9$. 
Results of the simulation of the 1906 main asperity compared with the simulation of the vertical strike-slip version of Loma Prieta are shown in Figure 22. The synthetic velocity and displacement waveforms are displayed in Figure 23 for a station adjacent to the fault trace. The peak ground velocity amplitudes are substantially greater than those recorded during the Loma Prieta earthquake, and are comparable to those predicted by Joyner and Boore (1988) for a $M_{W}=7.7$ earthquake. Again, the tangential components are dominant due to the along strike $S H$ pulse from a vertical strike-slip rupture. Because the station distribution is fairly random, several stations are off the southeast end of the rupture and show fairly small ground motions. This is attributed to the lack of directivity at southeastern stations, and the fact that we do not add in the contributions from adjacent portions of the fault. Recall, we model only a small $(40 \mathrm{~km})$ portion of the entire 1906 rupture and not the entire rupture length, so our durations are much shorter than would be expected. Here, we are more interested in the largest possible motions because of a magnitude $7 \frac{3}{4}$ earthquake, rather than the average ground motions. Considering the large amount of slip known to have occurred on adjacent segments, these contributions may be important, but would not significantly alter the estimation of the greatest contribution to the ground motions.

It seems that the Joyner and Boore (1988) curve is a fairly conservative estimate considering our data points represent the largest peak velocities expected from the greatest asperity. An overall average of stations along the length of the rupture would be considerably lower.

\section{Discussion AND CONCLUSIONS}

Using Morgan Hill observations as empirical Green's functions, we found that a majority of the shear wave train can be modeled with pure strike-slip on two energetic regions of the fault separated by about 40 sec. Assuming a uniform rupture velocity of $2.7 \mathrm{~km} / \mathrm{sec}$, this time corresponds to a distance separation of approximately $110 \mathrm{~km}$. The rupture velocity was chosen to be $2.7 \mathrm{~km} / \mathrm{sec}$ based on the average value determined from other studies of California strike-slip earthquakes (e.g., Hartzell and Heaton, 1983, 1986; Beroza and Spudich, 1986; Wald et al., 1990). This assumption fixes the final location of the major asperity relative to the hypocenter, and reasonable perturbations from this value (2.4 to $3.0 \mathrm{~km} / \mathrm{sec}$ ) do not change the synthetic waveforms significantly nor the scaling factor required to fit the data. Choosing a constant rupture velocity of 2.4 $\mathrm{km} / \mathrm{sec}$ has the effect of shifting the largest source of radiation about $12 \mathrm{~km}$ closer to the epicenter. We also assumed the rupture front propagates in a rather simple fashion because a more complex rupture scenario with repeated or delayed rupture episodes cannot be resolved based on the quality of the data available.

The locations of the two sources of strong 10 to 20 -sec radiation is consistent with Boore's (1977) observation that the source of the main strong motions observed at Mt. Hamilton was at least $75 \mathrm{~km}$ away. This corresponds with the location of the first main asperity in our 1906 source model. The second, larger asperity certainly contributed later in the record, but was radiated from a much greater distance, nearly $200 \mathrm{~km}$ away.

By comparing the slip model derived from the inversion (Fig. 17, top) with the surface offset and the modeled slip from the geodetic data (Fig. 17, bottom), we found a general correspondence between the hypocentral asperity and a gradi- 
1906 Estimate Vs. Lome Prieta VSS
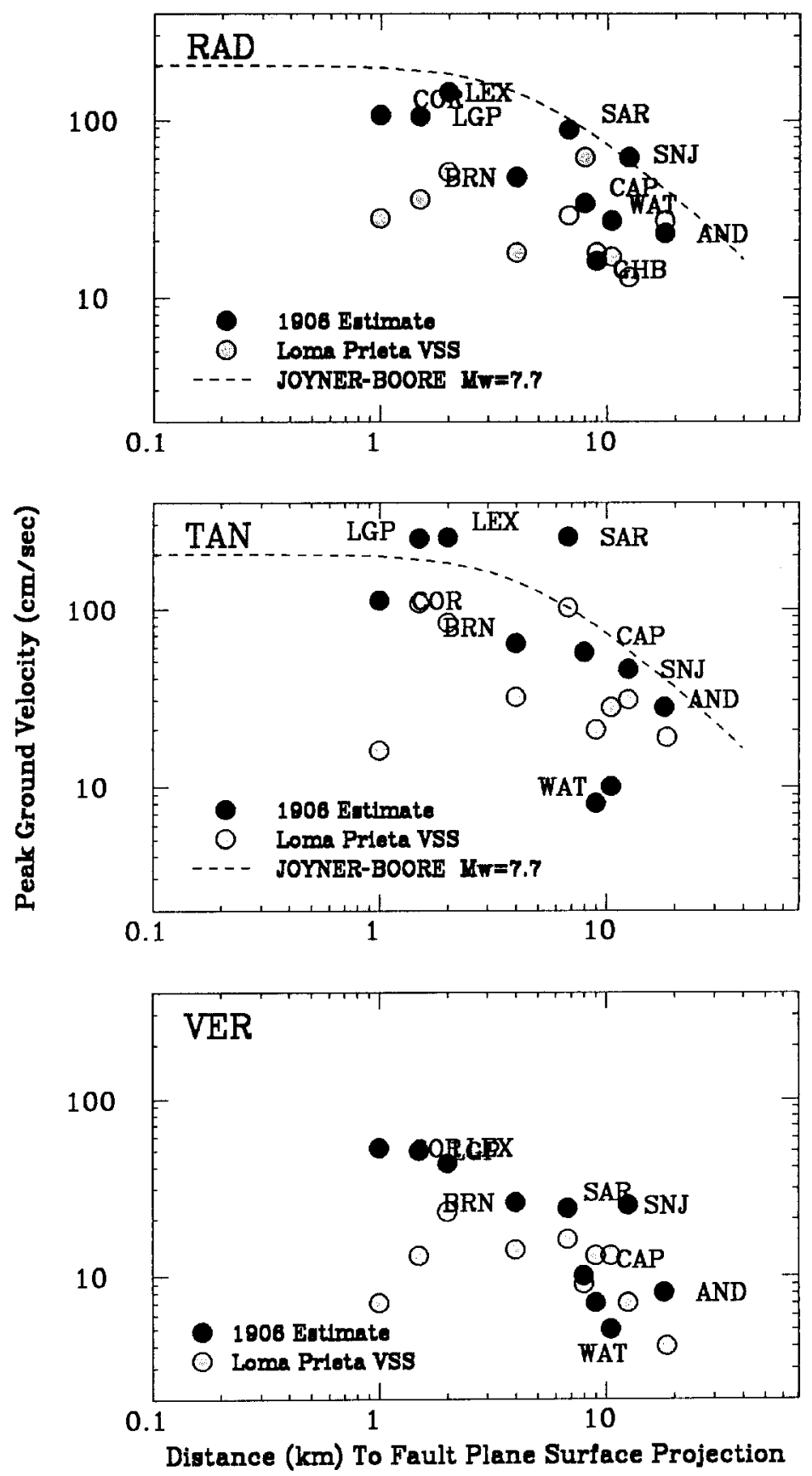

FIG. 22. Radial (top), tangential (middle), and vertical (bottom) peak ground velocities for simulations of the main 1906 asperity (solid circles) compared with the modified vertical strike-slip Loma Prieta model (shaded circles). The attenuation relationship of Joyner and Boore (1988) is given with the dashed line for $M_{w}=7.7$. 

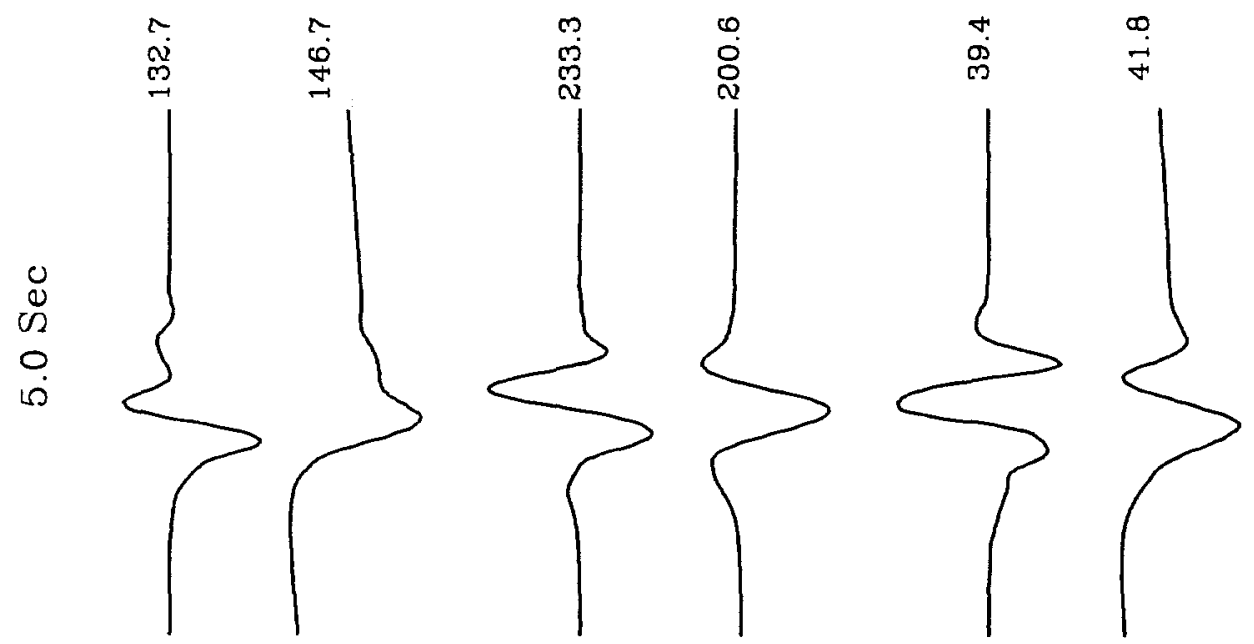

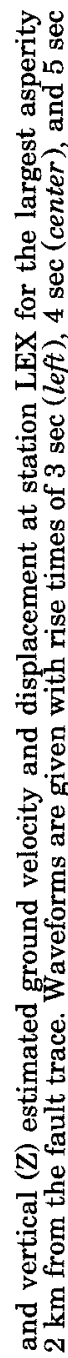
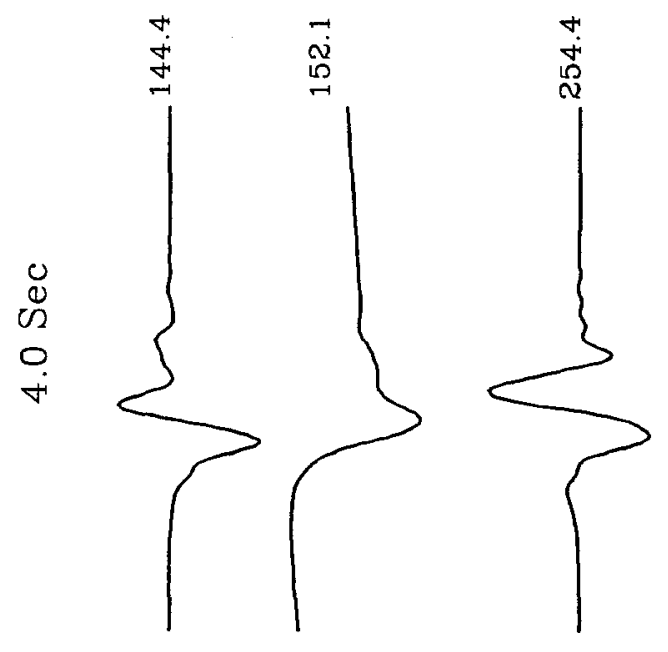

$\stackrel{\overrightarrow{-}}{\vec{a}}[$ 으

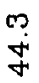
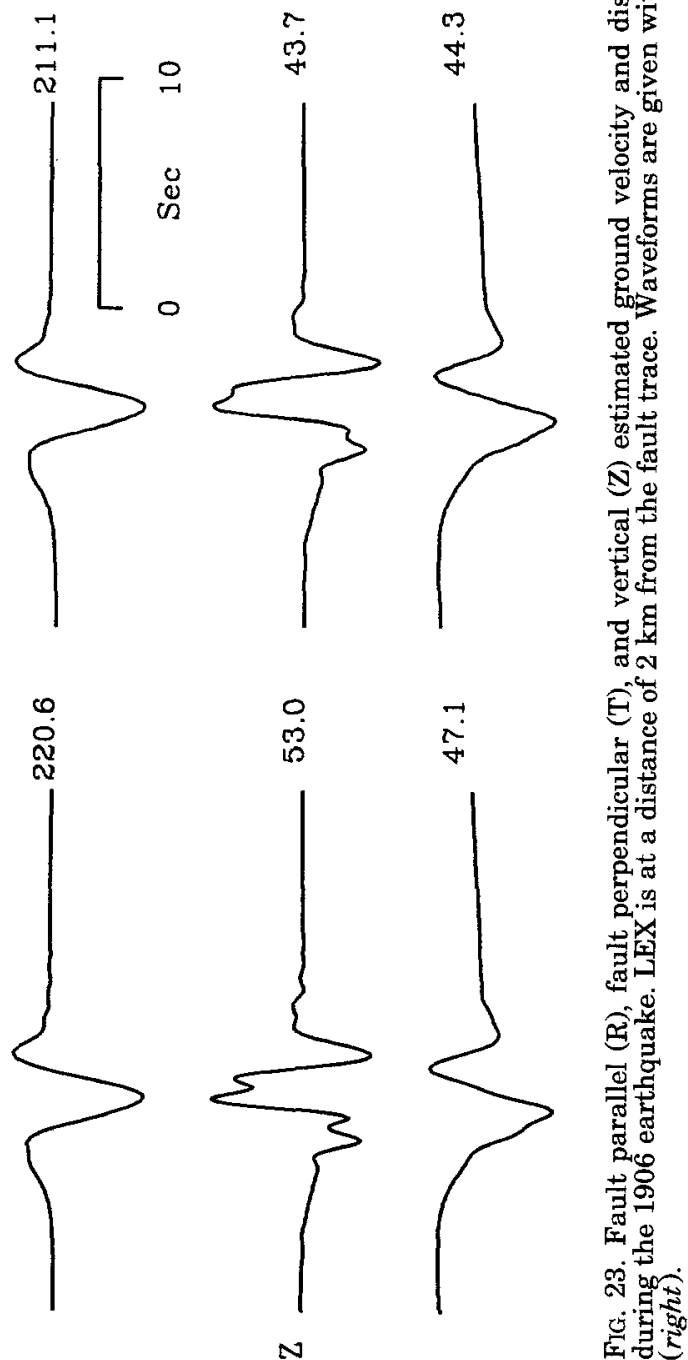

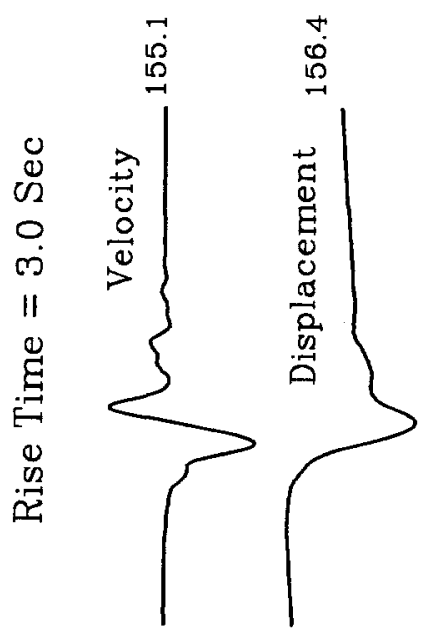

$\propto$

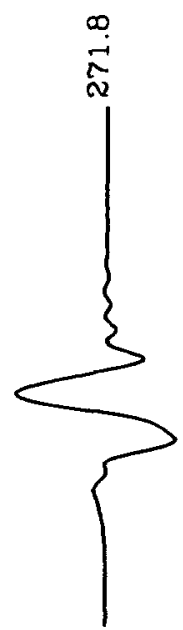

$E$

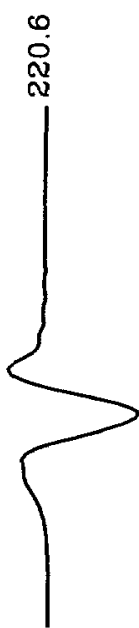

$\circ$

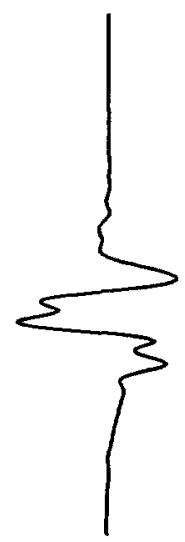

$N$

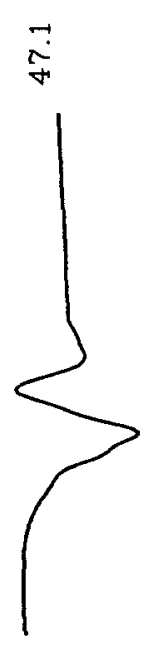

总魷 
ent in the amount of slip in the region. The larger asperity between Point Reyes and Fort Ross corresponds roughly with the region of largest surface offset and geodetic slip. Note that there may really be more variation in the static slip than suggested by the geodetic models. Thatcher (1975) assumed a constant slip with depth and a fixed depth of rupture along the fault. If the actual depth of rupture varied, or the functional form of the slip with depth is similar to other strike-slip earthquakes in California, that is a peak in slip at 8 to $9 \mathrm{~km}$ and tapering off both shallower and deeper, the solution to the geodetic displacements would be different.

Another factor that is difficult to evaluate is the effect of rupture dynamics on the teleseismic arrivals. Abrupt accelerations of the rupture front can result in starting and stopping phases on the teleseismic records. In effect, a model with uniform slip, tapered to zero at each end can produce complex records if the rupture front is inhibited and then allowed to re-accelerate a number of times. If rupture along the central portion of the 1906 rupture zone had a complex rupture progression, the total slip estimated in our model could be reduced. Likewise, a model with a relatively homogeneous slip and a constant rupture velocity might be difficult to recognize teleseismically because of uniformity of the radiation. It is likely that the offshore segment of the fault, ruptured in this fashion.

Simulated ground velocities were produced from our estimate of the largest asperity. In so doing, we have placed a few "data" points on the attenuation curve of Joyner and Boore (1988) which has few observational constraints for these close in distances and this large magnitude. Unfortunately, it seems that the distribution of Modified Mercalli intensities shown in Figure 2 provides little information about variations in the nature of the rupture as a function of position along strike, making it difficult to relate our model to the ground motions and damage experienced in 1906. Rather, the Modified Mercalli map shows a fairly uniform along strike distribution. This observation is also apparent in the full-sized isoseismal map (Rossi-Forel scale) given in the Atlas. As carefully noted by Lawson (1908), the most striking feature in the apparent intensity map is the correlation between the regions of strong shaking and the underlying geological conditions, particularly with river and sedimentary basins and reclaimed and tidal marsh lands. With the exception of the gradual decrease in intensity with increasing distance to the fault trace, this correlation dominates the variations in the intensities. We found no obvious independent constraints (i.e., density of topped trees or eyewitness accounts) on the variations in shaking intensity along strike.

It should be noted that there is no significant change in the nature of the surface expression of the San Andreas Fault in the region of maximum slip and radiation (between Point Reyes and Fort Ross) and, in fact, the fault tends to be simpler than along other portions of the San Andreas Fault. Hence, there is no correspondence between the largest asperity (or greatest slip) and surface fault trace complexity for the 1906 earthquake. There is, however, a substantial right-stepping (releasing) bend just north of the epicentral asperity west of the Golden Gate. This step-over is recognizable but not impressive on the scale of Figure 1.

We have not addressed the issue of dip-slip components in the vicinity of the Loma Prieta earthquake. From our modeling, we do not consider that the body wave data requires a significant component of dip-slip, although it is not clear 
that the historic seismic data can fully resolve this issue. Recent comparison of the horizontal displacements accompanying the 1906 San Francisco and the 1989 Loma Prieta earthquakes indicate that although the Loma Prieta event exhibited nearly equal strike- and dip-slip components of faulting, the 1906 data is consistent with strike-slip on a vertical plane (Segall and Lisowski, 1990). Likewise, although rupture along the northernmost $140 \mathrm{~km}$ of the San Andreas (offshore) is not observed in the teleseismic body wave arrivals, based on the historical data alone, we do have the resolving power to rule it out. Most likely, any slip along that portion of the fault was also relatively uniform and of low stress-drop.

Considering the enormous rupture length of 1906 compared with other large ruptures, more complexity in the waveforms might be expected. The above observations suggest relatively uniform slip on lengthy portions of the northern San Andreas Fault occurred during the 1906 rupture, and not 10 end-to-end "Loma Prieta" style ruptures. Because we can recognize the Loma Prieta rupture clearly on the Wiechert instruments at UPP and GOT, such a complex rupture would likely be recognizable on the historical records.

In contrast to the 1906 San Francisco earthquake, other large, continental strike-slip earthquakes have had considerably more rupture complexity. For example, comparison of WWSSN shear-wave amplitudes and waveforms for the 1976 Guatemala earthquake $\left(M_{S}=7.5\right)$ shows that the 1906 amplitudes are nearly three times larger, yet the waveforms are clearly less complicated. Based on the long-period WWSSN body waves, Kikuchi and Kanamori (1991) and Young et al. (1989) associated many large subevents during the Guatemalan earthquake with later arrivals in the teleseismic data. As with our model of the 1906 rupture, for the Guatemalan event, the region of greatest surface slip coincides roughly with the largest subevent of the Kikuchi and Kanamori (1991) rupture model. Although fairly continuous with few splays, the 1976 rupture trace follows an accurate route with a nearly $35^{\circ}$ change in strike over the rupture length (about $240 \mathrm{~km}$ ), perhaps contributing to the relative complexity and numerous identifiable subevents.

We have suggested that portions of the 1906 rupture occurred such that they did not produce large signals in the teleseismic recordings in a bandwidth of 5 to 20 sec. This does not necessarily imply that those portions of the rupture produced only relatively moderate high-frequency ground motions. In fact, this remains a pressing issue. Can a smooth rupture, as observed at 15 sec periods, be produced by a uniform, but short duration slip which is capable of radiating very damaging near-field motions? Alternatively, does the complexity of the 1976 Guatemala teleseismic recordings (Kikuchi and Kanamori, 1991) require that the local ground motions were comparably complex and damaging? Current data collections are not sufficient for fully addressing these questions; it will be interesting to independently analyze data sets from future large strike-slip earthquakes that are recorded at both teleseismic and local distances.

\section{ACKNOWLEDGMENTS}

We thank O. Kulhanek, K. Singh, and S. Duda for assistance with data collection. Neil Humphreys developed the digitizing software. Conversations with Mike Lisowski, Dorothy Merrits, Paul Segall, and David Schwartz were informative, and Stephen Hartzell provided assistance in the uncertainty estimation. The original manuscript was improved by Lisa Wald and Paul Somerville. A careful, critical review by Larry Ruff was appreciated and helped clarify the presentation. This work was 
supported by the NSF grant EAR9003464. Contribution number 5184 of the Division of Geological and Planetary Sciences, California Institute of Technology.

\section{REFERENCES}

Abe, K. and S. Noguchi (1983). Revision of large shallow earthquakes, 1897-1912, Phys. Earth Planet. Int., 33, 1-11.

Baag, C. and C. A. Langston (1985). Shear-coupled PL, Geophys. J. R. Astr. Soc. 80, 363-385.

Ben-Menahem, A. (1978). Source mechanism of the 1906 San Francisco earthquake, Phys. Earth and Planet. Int. 17, 163-181.

Bent, A. L., D. V. Helmberger, R. J. Stead, and P. Ho-Liu (1989). Waveform modeling of the 1987 Superstition Hills earthquake, Bull. Seism. Soc. Am. 79, 500-514.

Beroza, G. C. and P. Spudich (1988). Linearized inversion for fault rupture behavior: application to the 1984 Morgan Hill, California, earthquake, Bull. Seism. Soc. Am. 93, 6275-6296.

Bolt, B. A. (1968). The focus of the 1906 California earthquake, Bull. Seism. Soc. Am. 58, 457-471.

Boore, D. M. (1977). Strong motion recordings of the California earthquake of April 16, 1906, Bull. Seism. Soc. Am. 67, 561-576.

Ekström, G. (1984). Centroid-moment tensor solution for the April 24, 1984 Morgan Hill earthquake, in The 1984 Morgan Hill, California Earthquake, CDMG Special Publication 68.

Gutenberg, B. (1955). Magnitude determination for larger Kern County shocks, 1952; effects of station azimuth and calculation methods, in Earthquakes in Kern County, California during 1952, Cal. Div. Mines Geol. Bull. 171, 171-176.

Hartzell, S. H. and T. H. Heaton (1983). Inversion of strong ground motion and teleseismic waveform data for the fault rupture history of the 1979 Imperial Valley, California earthquake, Bull. Seism. Soc. Am. 73, 1553-1583.

Hartzell, S. H. and T. H. Heaton (1986). Rupture history of the 1984 Morgan Hill, California, earthquake from the inversion of strong motion records, Bull. Seism. Soc. Am. 76, 649-674.

Hartzell, S. H. and M. Iida (1990). Source complexity of the 1987 Whittier Narrows, California, Earthquake from the inversion of strong motion records, J. Geophys. Res. 95, 12,475-12,485.

Heaton, T. H. (1990). Evidence for and implications of self-healing pulses of slip in earthquake rupture, Phys. Earth Planet. Inter. 64, 1-20.

Helmberger, D. V., P. G. Somerville, and E. Garnero (1992). The location and mechanism of the Lompoc, California earthquake of 4 November, 1927, Bull. Seism. Soc. Am. 82, 1678-1709.

Jeffreys, H. and K. E. Bullen (1958). Seismological Tables, Office of the British Association, Burlington House, London.

Jennings, P. C. and H. Kanamori (1979). Determination of local magnitude, $M_{L}$, from seismoscope records, Bull. Seism. Soc. Am. 69, 1267-1288.

Joyner, W. B. and D. M. Boore (1988). Measurement, characterization, and prediction of strong ground motion, in: Proceedings of the Earthquake Engineering and Soil Dynamics II Conference, American Society of Civil Engineers, Geotechnical Special Publication No. 20, 43-102.

Kikuchi, M. and H. Kanamori (1991). Inversion of Complex Body Waves-III, Bull. Seism. Soc. Am. 81, 2335-235.

Lawson, A. C., chairman (1908). The California earthquake of April 18, 1906: Rep. State Earthquake Invest. Comm. Vols. I and II; Atlas, Carnegie Inst., Washington, D.C.

Liu, H. and D. V. Helmberger (1983). The near-source ground motion of the August, 1979 Coyote Lake, California, earthquake, Bull. Seism. Soc. Am. 73, 201-218.

McLaughlin, R. J., D. H. Sorg, J. L. Morton, J. N. Batchelder, R. A. Leveque, C. Heropoulus, H. N. Ohlin, and M. B. Norman (1979). EOS 60, 883.

Olson, A. and R. Apsel (1982). Finite faults and inverse theory with applications to the 1979 Imperial Valley earthquake, Bull. Seism. Soc. Am. 72, 1969-2001.

Prentice, C. S. and D. P. Schwartz (1991). Re-evaluation of 1906 surface faulting, geomorphic expression, and seismic hazard along the San Andreas fault in the southern Santa Cruz Mountains, Bull. Seism. Soc. Am. 81, 1424-1479.

Reid, H. F. (1910). The Mechanics of the Earthquake, Vol. II of The California Earthquake of April 18, 1906, Carnegie Institution of Washington (reprinted 1969), $192 \mathrm{pp}$.

Richter, C. F. (1958). Elementary Seismology, W. H. Freeman and Company, San Francisco and London, $768 \mathrm{pp}$.

Segall, P. and M. Lisowski (1990). Comparison of surface displacements in the 1906 San Francisco and 1989 Loma Prieta earthquakes, Science 250, 1241-1244. 
Thatcher, W. and M. Lisowski (1987a). 1906 earthquake slip on the San Andreas fault in offshore northwestern California, EOS 68, 1507.

Thatcher, W. and M. Lisowski (1987b). Long-term seismic potential of the San Andreas fault southeast of San Francisco, California, J. Geophys. Res. 92, 4771-4784.

Thatcher, W. (1975). Strain accumulation and release mechanism of the 1906 San Francisco earthquake, J. Geophys. Res. 80, 4862-4872.

Thatcher, W. (1975). Strain accumulation on the northern San Andreas fault zone since 1906, $J$. Geophys. Res. 80, 4873-4880.

Toppozada, T. R. and D. L. Parke (1982). Areas damaged by California earthquakes, 1900-1949, California Division of Mines and Geology, Open-File Rept. 82-17 SAC.

Wald, D. J., S. H. Hartzell, and D. V. Helmberger (1990). Rupture process of the 1987 Superstition Hills earthquake from the inversion of strong motion data, Bull. Seism. Soc. Am. 80, 1079-1098.

Wald, D. J., S. H. Heaton, and D. V. Helmberger (1991). Rupture model of the 1989 Loma Prieta earthquake from the inversion of strong motion and broadband teleseismic data, Bull. Seism. Soc. Am. 81, 1540-1572.

Wald, D. J., T. H. Heaton, and D. V. Helmberger (1992). Strong Motion and Broadband Teleseismic Analysis of the 1989 Loma Prieta Earthquake for Rupture Process and Hazards Assessment, submitted to U.S.G.S. Professional Paper, January, 1992.

Young, C. J., T. Lay, and C. S. Lynnes (1989). Rupture of the 4 February 1976 Guatemalan earthquake, Bull. Seism. Soc. Am. 79, 670-689.

SEISMOLOGiCAL LaboRATORY 252-21

California Institute of Technology (D.J.W., H.K., D.V.H.)

Manuscript received 6 July 1992
U.S. Geological Survey, Pasadena (T.H.H.) 